Rebeca Bayeh

Estudo das Propriedades Acústicas e Psicofísicas da Cóclea 



\author{
Universidade de São Paulo \\ Instituto de Física
}

\title{
Estudo das Propriedades Acústicas e Psicofísicas da Cóclea
}

\author{
Rebeca Bayeh
}

Orientador: Prof. Dr. Walter Maigon Pontuschka

Dissertação de mestrado apresentada ao Instituto de Física como requisito parcial para a obtenção do título de Mestre em Ciências.

Banca Examinadora:

Prof. Dr. Walter Maigon Pontuschka (IFUSP)

Prof. Dr. Oscar João Abdonour (IME/USP)

Profa. Dra. Christiane Marques do Couto (UNICAMP) 


\author{
University of São Paulo \\ Physics Institute
}

\title{
Study on the Acoustical and Psychophysical Properties of the Cochlea
}

\author{
Rebeca Bayeh
}

Supervisor: Prof. Dr. Walter Maigon Pontuschka

Dissertation submitted to the Physics Institute of the University of São Paulo in partial fulfillment of the requirements for the degree of Master of Science.

Examining Committee:

Prof. Dr. Walter Maigon Pontuschka (IFUSP)

Prof. Dr. Oscar João Abdonour (IME/USP)

Prof. Dr. Christiane Marques do Couto (UNICAMP) 


\section{FICHA CATALOGRÁFICA}

\section{Preparada pelo Serviço de Biblioteca e Informação}

do Instituto de Física da Universidade de São Paulo

\section{Bayeh, Rebeca}

Estudo das propriedades acústicas e psicofísicas da Cóclea. São Paulo, 2018.

Dissertação (Mestrado) - Universidade de São Paulo. Instituto de Física. Depto. de Física Geral

Orientador: Prof. Dr. Walter Maigon Pontuschka

Área de Concentração: Física

Unitermos: 1. Acústica; 2. Orelha; 3. Psicoacústica; 4. Acústica musical; 5. Computação musical 
A todas as mulheres

que ousam fazer ciência, arte e política 


\section{Agradecimentos}

Ao Prof. Walter Maigon Pontuschka pela orientação, pelos ensinamentos acadêmicos, pelos ensinamentos humanos, pela paciência e pelo exemplo de humanidade dentro da academia científica;

à minha avó Salma Ibrahim, cujo apoio e suporte foram absolutamente fundamentais ao longo deste trabalho, à minha mãe Lina Nasrallah e ao meu pai Sarkis Joud Bayeh por terem estimulado em mim o pensamento científico desde os primórdios, a meus irmãos Barbara Bayeh e Joud Bayeh, pelo apoio incondicional e pela fé em meu potencial, à Denise Velasco Figueiredo por ter participado ativamente de minha história com a Física desde o início;

ao meu companheiro Eduardo Veríssimo Freita da Silva que, parceiro de todas as horas, esteve ao meu lado durante todos os melhores e todos os piores momentos, independentemente das circunstâncias;

à minha tia Maria Joud Bayeh (in memoriam) que, sendo parte de mim, é parte deste trabalho;

ao amigo e parceiro de trabalho Micael Antunes da Silva, por me inspirar, motivar e me ajudar a encontrar um propósito para este trabalho, por todas as ideias e contribuições, por todas as horas de trabalho, pesquisa, jornadas internacionais acadêmicas e pela parceria incrível;

aos meus antigos orientadores, Prof. José Roberto Martinelli (in memoriam) e Prof. Ronald D. P. K. C. Ranvaud pelos preciosos ensinamentos e estímulos intelectuais ao longo de minha jornada acadêmica;

ao professor Maurício Nacib Pontuschka pela generosa contribuição nos cálculos utilizados neste trabalho;

ao professor Regis Rossi Alves Faria por todos os comentários, contribuições, apoio e acolhimento no NEAC;

ao Grupo de Estudos Musicológicos Sant'Anna Gomes, em especial à Sra. Dulce Míriam Schmidt, pelo entusiasmo, interdisciplinaridade e acolhimento, e ao Sr. Adhemar Petri Filho (in memoriam) por ter me apresentado ao universo da musicologia e por ter me motivado a seguir com minhas jornadas na ciência e na arte;

à amiga Cibele Barbalho Assêncio, por inumeráveis razões, dentre as quais os preciosos conselhos e as longas madrugadas de produtividade;

aos queridos amigos Douglas Nunes Vieira, Natalie e Sá, Daniele Dionizio e Fe- 
lipe Velasquez que, tendo me acompanhado por tantos anos, trouxeram sentido, alegria, esperança e a lembrança do que realmente é importante em qualquer jornada;

aos professores Fábio Leão Figueiredo, Maria Inês Nogueira e Ricardo Bento Ferreira pelas generosas contribuições e inspirações;

à querida amiga Elisabete Nunes Medeiros pelo acolhimento incondicional e pela lembrança constante da necessidade de vivenciar a arte em conjunto com o pensamento racional;

à querida Eliana Haller Monteiro pelo lindo trabalho, que foi de grande importância em minha busca por sentido, e por me auxiliar a me apropriar de minhas próprias capacidades profissionais e potenciais humanos;

aos meus colegas Adriana Camargo Brito, Elisa Morande Sales, Cristina Yukari Kawakita Ikeda, João Heitzmann Fontanelle, Marcelo de Mello Aquilino e Maria Akutsu, do Laboratório de Conforto Ambiental do Instituto de Pesquisas Tecnológicas (LCA IPT) que me ensinaram a enxergar a Acústica e a academia através de novas perspectivas, com generosidade e acolhimento;

à equipe "abnTEX2"por este template e a todos os entusiastas do open source que participaram direta e indiretamente deste trabalho;

à Alexandra Elbakyan, criadora do Sci Hub, e a todos os entusiastas da ciência aberta e livre;

aos colegas com quem cursei as disciplinas obrigatórias, pelo companheirismo e trabalho em equipe, ao Lucas Carpinelli Nogueira da Silva pela parceria na disciplina "Bases Cognitivas da Percepção Musical"e pela inspiração filosófica, e aos caros amigos Adriana Valerio, Milena Khouri, Edi Carlos Sousa, Carlos Eduardo Freitas, Atenágoras Silva e Francisco Garanhani pelos bons momentos e cumplicidade;

aos funcionários do Departamento de Física Geral, em especial ao Sr. José Valdir e à Sra. Edineusa, e da Comissão de Pós-Graduação, em especial ao Sr. Eber pelo apoio fundamental, pela gentileza, humanidade e disponibilidade;

à Comissão de Pós-Graduação pelo auxílio fundamental para minha participação no International Symposium on Computer Music Multidisciplinary Research (CMMR) em Portugal e pelo maravilhoso curso de inglês oferecido, e à professora Gláucia Fernandes pela inspiração profissional e humana e pelo apoio e generosidade ao ensinar;

à Coordenação de Aperfeiçoamento de Pessoal de Nível Superior (CAPES) pelo fomento;

ao Instituto de Física da Universidade de São Paulo pelos bons ensinamentos e pela contribuição fundamental ao meu fortalecimento moral. 
"Homem algum poderá revelar-vos senão o que já está meio adormecido na aurora do vosso entendimento. O mestre que caminha à sombra do templo, rodeado de discípulos, não dá de sua sabedoria, mas sim de sua fé e de sua ternura. Se ele for verdadeiramente sério, não vos convidará a entrar na mansão de seu saber, mas vos conduzirá antes ao limiar de vossa própria mente. O astrônomo poderá falar-vos de sua compreensão do espaço, mas não vos poderá dar a sua compreensão.

O músico poderá cantar para vós o ritmo que existe em todo o universo, mas não vos poderá dar o ouvido que capta a melodia, nem a voz que a repete. E o versado na ciência dos números poderá falar-vos do mundo dos pesos e das medidas, mas não vos poderá levar até lá,

Porque a visão de um homem não empresta suas asas a outro homem."

(Gibran Khalil Gibran) 



\section{Resumo}

O presente trabalho tem como objetivo apresentar uma revisão bibliográfica de alguns dos principais conceitos acústicos e psicoacústicos associados à audição humana já desenvolvidos na literatura, de Helmholtz aos dias atuais, com foco no órgão da cóclea, dialogando com as áreas de física, neurociências e computação musical, bem como aplicações diretamente derivadas de tal revisão. A partir dos cálculos realizados por Couto (COUTO, 2000) de distribuição da pressão sonora no meato acústico externo, foi calculada a pressão sonora relativa e a impedância acústica ao longo do órgão coclear. Também é apresentado um algoritmo de minimização da dissonância sensorial baseado nos modelos de bandas críticas de Cambridge e de Munique, bem como uma implementação de tal algoritmo.

Palavras-chaves: acústica. orelha. acústica musical. psicoacústica. computação musical. 



\section{Abstract}

The present work presents a literature review on some of the most important acoustical and psychoacoustical concepts associated to human hearing, from Helmholtz (HELMHOLTZ, 1954) to the present day, focusing on the cochlea and connecting concepts of physics, neurosciences and computer music, as well as applications directly derived from such concepts. Based on the sound pressure distribution model developed by Couto (COUTO, 2000), the relative sound pressure and the acoustic impedance along the cochlea were calculated. An algorithm for minimizing sensory dissonance based on Cambridge and Munich models of critical bandwidths and an implementation of such algorithm are also presented.

Key-words: acoustics. human ear. musical acoustics. psychoacoustics. computer music. 



\section{Lista de ilustrações}

Figura 1 - Ilustração esquemática da orelha humana. 1. Crânio; 2. Canal auditivo; 3. Pavilhão Auricular; 4. Membrana timpânica; 5. Janela oval; 6. Martelo; 7. Bigorna; 8. Estribo; 9. Labirinto; 10. Cóclea; 11. Nervo auditivo; 12. Tubo de Eustáquio. Retirado de Wikimedia Commons (WIKIMEDIA, 2013). . . . . . . . . . . . . . . . . . . . . . 29

Figura 2 - Ilustração do bloco labiríntico. Reproduzido de Bento et al. (BENTO; MINITI; MARONE, 1998) com autorização do autor. . . . . . . . . . . 32

Figura 3 - Imagem de corte da cóclea. Reproduzido de Bento et al. (BENTO; MINITI; MARONE, 1998) com autorização do autor. . . . . . . . . . . 32

Figura 4 - Reconstrução de uma cóclea. Reproduzido de Rask-Andersen et al. (RASK-ANDERSEN et al., 2012). . . . . . . . . . . . . . . 33

Figura 5 - Esquema ilustrativo do deslocamento da membrana basilar em quatro momentos consecutivos, da esquerda para a direita. A linha tracejada indica o envelope formado pelos picos de amplitude. Adaptado de Moore $($ MOORE, 2012) . . . . . . . . . . . . . . . . . . . 34

Figura 6 - Esquema das células ciliadas. Sobre os cílios existe uma camada gelatinosa que contém granulações calcárias denominadas oto-cônicas. Reproduzido de Bento et al. (BENTO; MINITI; MARONE, 1998) com autorização do autor.

Figura 7 - Comparação entre modelos de deslocamento induzido na membrana timpânica. Reproduzido de Purial \& Rosowski (PURIA; ROSOWSKI, 2012), adaptado de Tonndorf \& Khanna (TONNDORF; KHANNA, 1972) 40

Figura 8 - Representação gráfica da escala de Barks proposta por Zwicker. O eixo horizontal representa o número da banda e o eixo vertical, em escala logarítmica, indica as frequências correspondentes. Adaptado de Wiki Media Commons (WIKIMEDIA, 2016).

Figura 9 - Relação entre posição na membrana basilar (mm), bandas críticas (Bark) e frequência $(\mathrm{Hz})$. Adaptado de The Speech Recognition Wiki (MAI-

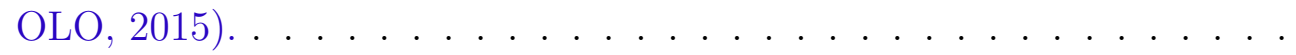

Figura 10 -Ilustração esquemática dos segmentos da cóclea utilizados para o cálculo da distribuição da pressão sonora, baseada na fotografia de réplica coclear publicada por Rask-Anderser et al. (RASK-ANDERSEN et al., 2012) 
Figura 11 -Diagrama esquemático do algoritmo de síntese de timbres reduzindo-se a dissonância sensorial em escalas com temperamento por igual. . . . . 54

Figura 12 - Gráfico de pressão sonora relativa ao longo do eixo central da cóclea para as frequências $3 k H z, 5 k H z, 10 k H z$ e $20 k H z . \ldots . . . .55$

Figura 13 - Gráfico de impedância acústica ao longo do eixo central da cóclea para as frequências $3 k H z, 5 k H z, 10 k H z$ e $20 k H z$. . . . . . . . . . 56

Figura 14 - Comparação entre números de banda crítica entre as escalas de Munique (em Barks) e de Cambridge (em Cams). . . . . . . . . . . . . 57

Figura 15 - Saída do programa desenvolvido para frequências de entrada $100 \mathrm{~Hz}$, $200 \mathrm{~Hz}, 300 \mathrm{~Hz}, 400 \mathrm{~Hz}, 500 \mathrm{~Hz}, 600 \mathrm{~Hz}, 700 \mathrm{~Hz}$ e $800 \mathrm{~Hz}$. . . . . 58

Figura 16 -Curvas de dissonância do espectro de frequências original e dos dois espectros filtrados utilizando-se os modelos de Munique e de Cambridge. 58

Figura 17 -Curvas de dissonância correspondentes às frequências iniciais $440 \mathrm{~Hz}$ (esquerda) e 1760Hz (direita). Reproduzido de (SILVA; BAYEH; FARIA, 2017). . . . . . . . . . . . . . . . . . . 59 


\section{Lista de tabelas}

Tabela 1 - Tabela de bandas críticas em escala Bark, traduzido e adaptado de Zwicker (ZWICKER, 1961) . . . . . . . . . . . . . 69

Tabela 2 - Posições na cóclea e áreas das secções transversais estimadas para realização do cálculo de pressão sonora relativa e impedância acústica. 71

Tabela 3 - Valores calculados de pressão sonora relativa e impedância acústica para as frequências $3 k H z$ e $5 k H z$. . . . . . . . . . . . . . 72

Tabela 4 - Valores calculados de pressão sonora relativa e impedância acústica para as frequências $10 k H z$ e $20 k H z$. . . . . . . . . . . . 73 



\section{Lista de abreviaturas e siglas}

\begin{tabular}{|c|c|}
\hline $\mathrm{f}$ & Frequência \\
\hline $\mathrm{Hz}$ & Hertz \\
\hline $\mathrm{kHz}$ & Quilo-Hertz \\
\hline $\log$ & Logaritmo comum (base 10) \\
\hline $\ln$ & Logaritmo natural (base $e$ ) \\
\hline $\mathrm{x}$ & Posição na membrana basilar ou na cóclea \\
\hline $\mathrm{p}$ & Pressão sonora \\
\hline $\mathrm{Z}$ & Impedância acústica \\
\hline $\mathrm{kg}$ & Quilograma \\
\hline 1 & Loudness \\
\hline $\mathrm{dB}$ & Decibel \\
\hline $\mathrm{k}$ & Número de onda \\
\hline $\mathrm{T}$ & Período \\
\hline $\mathrm{z}$ & Número da banda crítica \\
\hline Bark & Bark (unidade de número de banda crítica) \\
\hline Cam & Cam (unidade de número de banda crítica) \\
\hline asper & Asper (unidade de rugosidade) \\
\hline $\mathrm{A}$ & Área \\
\hline $\mathrm{u}$ & Velocidade \\
\hline $\mathrm{m}$ & Metro \\
\hline $\mathrm{cm}$ & Centímetro \\
\hline $\mathrm{mm}$ & Milímetro \\
\hline$v_{s}$ & Velocidade do som \\
\hline
\end{tabular}


Segmento de trajetória curvilínea

$\min$

Mínimo

$b_{n}$

Parâmetros para cálculo de dissonância sensorial

$s_{n}$

Parâmetros para cálculo de dissonância sensorial

$x^{*} \quad$ Parâmetro para cálculo de dissonância sensorial

$d$

Dissonância sensorial para um par de tons puros

$D$

Dissonância sensorial para mais de um par de tons puros 


\section{Lista de símbolos}

$\begin{array}{ll}\Delta & \text { Diferença } \\ \sum & \text { Somatória } \\ \omega & \text { Velocidade angular } \\ \lambda & \text { Comprimento de onda } \\ \pi & \text { Número pi } \\ \rho & \text { Densidade } \\ \sigma & \text { Área estimada da secção transversal }\end{array}$





\section{Sumário}

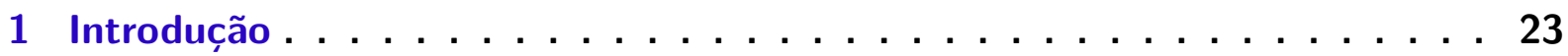

1.1 Motivação e Objetivos . . . . . . . . . . . . . . . . . . . 23

1.2 Som, Audição, Orelha Humana . . . . . . . . . . . . . . . . . . . . 23

1.3 A Orelha e a Cóclea . . . . . . . . . . . . . . . . . . . 24

I Fundamentação Teórica e Revisão Bibliográfica 27

2 A Orelha Humana . . . . . . . . . . . . . . . . . 29

2.1 Orelha Externa . . . . . . . . . . . . . . . . . . . . . . . . 29

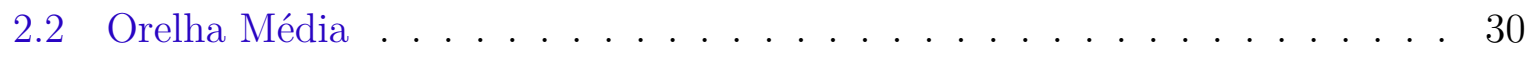

2.3 Orelha Interna . . . . . . . . . . . . . . . . . . . . . . . . 31

2.4 Cóclea, Membrana Basilar e Órgão de Corti . . . . . . . . . . . . . . . 31

3 Conceitos de Acústica e Psicoacústica . . . . . . . . . . . . . . 37

3.1 Cálculo da Distribuição da Pressão Sonora na Cóclea . . . . . . . . . . 37

3.2 Contribuições de Helmholtz . . . . . . . . . . . . . . . . . . . 38

3.3 Contribuições de Békésy . . . . . . . . . . . . . . . . . . . . . . 39

3.4 Breve Discussão sobre o Timbre . . . . . . . . . . . . . . . . . . 40

4 Propriedades Psicoacústicas da Cóclea . . . . . . . . . . . . . . . . 43

4.1 Mascaramento e Bandas Críticas . . . . . . . . . . . . . . . 43

4.2 Combinações de Tons, Batimentos e Rugosidade . . . . . . . . . . . . . 45

4.3 Dissonância Sensorial . . . . . . . . . . . . . . . . . . . . . . . . 46

$\begin{array}{ll}\text { II Aplicações } & 49\end{array}$

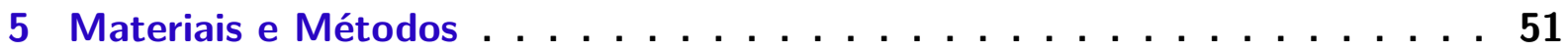

5.1 Cálculo da Distribuição da Pressão Sonora na Cóclea . . . . . . . . . . . . 51

5.2 Desenvolvimento de Algoritmo Baseado em Modelos de Bandas Críticas . . 52

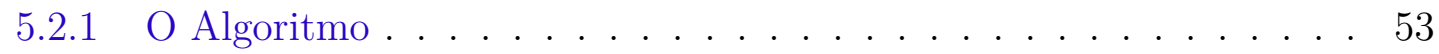

5.2.1.1 Aplicação - Escalas Temperadas Arbitrárias . . . . . . . . 53

5.2.1.2 Comparação entre os Modelos de Munique e de Cambridge 54

6 Resultados e Discussão . . . . . . . . . . . . . . . . . . . . . 55

6.1 Cálculo da pressão sonora ao longo do percurso central da cóclea . . . . . . 55

6.2 Aplicação do Algoritmo Baseado em Modelos de Bandas Críticas . . . . . . 57 
6.2.1 Comparação entre os Modelos de Banda Crítica . . . . . . . . . . . 57

6.2.2 Aplicação do Algoritmo a Escalas Temperadas Igualmente Temperadas . . . . . . . . . . . . . . . . . . . . 59

7 Conclusões . . . . . . . . . . . . . . . . . . . . . 61

7.1 Propriedades Acústicas e Psicoacústicas da Cóclea . . . . . . . . . . . . . . 61

7.2 Trabalhos Futuros e Considerações Finais . . . . . . . . . . . . . . . . . 61

Referências .......................... . 63

$\begin{array}{ll}\text { Apêndices } & 67\end{array}$

APÊNDICE A Escala de Bark - Zwicker . . . . . . . . . . . . . . 69

APÊNDICE B Cálculo da Distribuição da Pressão Sonora . . . . . . . . . . . 71

Anexos

ANEXO A Artigo Apresentado - CMMR $2017 \ldots \ldots 7$

ANEXO B Artigo Apresentado - CICTeM 2017 . . . . . . . . . . . . 87

ANEXO C Código em C - Cálculo e Filtragem de Bandas Críticas . . . . . . 93

ANEXO D Códigos em MatLab - Curvas de Dissonância . . . . . . . . . . . . 97 


\section{Introdução}

\subsection{Motivação e Objetivos}

A audição é um sentido de fundamental importância na mediação de nossa relação com o mundo e representa naturalmente um objeto de interesse para as mais diversas áreas do conhecimento, sejam científicas ou artísticas.

O presente trabalho, desenvolvido no Instituto de Física da Universidade de São Paulo, com colaboração de profissionais das áreas de música, engenharia, neurociências e medicina, tem como objetivos a apresentação de uma revisão bibliográfica multidisciplinar sobre alguns dos principais fenômenos físicos e psicofísicos associados à cóclea, o cálculo da pressão sonora e da impedância acústica ao longo do canal coclear e o desenvolvimento e aplicação de um algoritmo de minimização da dissonância sensorial tendo como base dois modelos de bandas críticas.

Busca-se facilitar o acesso à bibliografia relacionada a fenômenos acústicos e psicoacústicos associados à cóclea, não apenas para físicos, mas também para musicistas, matemáticos, cientistas da computação, neurocientistas, engenheiros e profissionais de áreas correlatas, visando integrar tais áreas do conhecimento e facilitar o desenvolvimento de novos projetos tanto nos campos das ciências biológicas quanto no desenvolvimento de novas tecnologias para aplicações científicas e artísticas.

Também ambiciona-se contribuir modestamente na promoção do diálogo entre tais áreas do conhecimento, diálogo este fortemente almejado mas ainda imaturo na comunidade científica, no que diz respeito à compreensão de nossa relação com o som.

\subsection{Som, Audição, Orelha Humana}

O termo "som"refere-se à perturbação vibratória do ambiente que excita o sistema auditivo, e está relacionado portanto à natureza do estímulo sonoro (ondas sonoras) e à estrutura biológica responsável pela audição, a orelha, no caso dos humanos.

No curso da evolução, a audição ofereceu enorme vantagem adaptativa, pois possibilitou a detecção de vibrações do ar e da água causadas por outros animais e o desenvolvimento de um sistema de comunicação através de vocalização. O sistema auditivo dos animais tornou-se mais complexo e miniaturizado ao longo da evolução (LENT, 2004).

O órgão da orelha é sensível a estímulos sonoros e também a efeitos da gravidade e de movimentação da cabeça. A transdução do sinal sonoro para mecânico dá-se na 
membrana timpânica, e o sinal mecânico é por sua vez convertido para elétrico no órgão de Corti, localizado no interior da estrutura coclear (RUGGERO, 1992; RUGGERO; RICH, 1991a). Durante a transmissão do som nas orelhas externa e média, fenômenos de ressonância resultam em amplificação de algumas frequências em detrimento de outras (COUTO, 2004). Dessa forma, escutamos melhor ou pior determinadas frequências, mesmo que elas cheguem à orelha com exatamente a mesma intensidade.

Esta distorção, assim como a faixa de frequências perceptíveis, varia sutilmente entre um indivíduo e outro, e geralmente varia muito entre uma espécie e outra. O espectro audível por humanos recém-nascidos é tido como o intervalo entre $20 \mathrm{~Hz}$ e $20 \mathrm{kHz}$, sendo que abaixo de $20 \mathrm{~Hz}$ a percepção passa a ser rítmica, e não de altura. Outras espécies de mamíferos possuem capacidade de escutar outras faixas de frequência, como espécies de elefantes e baleias, que escutam a partir de $15 \mathrm{~Hz}$ ou cachorros, que escutam até $40 \mathrm{kHz}$ (LENT, 2004).

Um estudo recente (SONG et al., 2016) avaliou a percepção de frequências em macacos da espécie Callithrix jacchus, nativa do Brasil e portanto considerada uma espécie de primata do "novo mundo", e constatou algumas similaridades entre sua audição com a audição humana. Os primatas foram treinados previamente para responder a variações nas frequências fundamentais de notas executadas, e em seguida foram submetidos a uma série de experimentos que utilizaram estímulos com diversas variações harmônicas e temporais. Um dos resultados obtidos foi que esta espécie de macaco apresenta sensibilidade à qualidade espectral (proporções entre intensidades dos parciais) e temporal similar à de humanos. As semelhanças encontradas pelo estudo sugerem que a nossa percepção de alturas teria se desenvolvido em estágios evolutivos no mínimo tão antigos quanto a separação entre as espécies de primatas "do novo mundo" e "do velho mundo", há aproximadamente 40 milhões de anos. Contudo, para uma avaliação mais precisa desta interpretação, será necessário avaliar a percepção de frequências em outros primatas (SONG et al., 2016).

\subsection{A Orelha e a Cóclea}

A cóclea, localizada na orelha interna, contém três dutos - a rampa vestibular, a rampa timpânica e o duto coclear, separado da primeira pela membrana de Reissner e da segunda pela membrana basilar. Sobre a membrana basilar encontra-se o órgão de Corti, constituído por células de sustentação e células ciliadas, distribuídas em seis fileiras.

A janela redonda, localizada no final da cóclea, funciona como um pistão que, ao oscilar, induz uma onda na membrana basilar que resulta por interferência de ondas em uma resultante cuja amplitude máxima depende da frequência do sinal sonoro de entrada. Desta forma, cada região da membrana basilar, imersa em uma solução aquosa, responde a uma determinada faixa de frequências. 
Os esterocílios das células capilares externas do órgão de Corti disparam um sinal elétrico de forma a contrair as células motoras da membrana basilar provocando então uma reação mecânica em fase de tais células, reforçando hidrodinamicamente, através da membrana tectorial, a oscilação local da membrana basilar (BENTO; MINITI; MARONE, 1998).

As vibrações da membrana iniciam-se em sua base e propagam-se no sentido de seu ápice. Quanto maior a frequência do som, menor é a região da membrana que vibra em resposta ao estímulo.

Sons de baixa frequência ativam preferencialmente as células ciliadas situadas nas porções apicais da membrana, enquanto sons de alta frequência ativam preferencialmente as células ciliadas localizadas nas porções basais, de forma que diferentes populações neuronais são mobilizadas de acordo com a faixa de frequência do som (ROEDERER, 1995).

É possível portanto fazer, como apontou Helmholtz em "On the Sensations of Tone as a Physiological Basis for the Theory of Music", uma analogia entre a resposta da membrana basilar a diferentes faixas de frequência e uma decomposição do sinal utilizando a transformada de Fourier (HELMHOLTZ, 1954).

Este conceito foi responsável pela elaboração de diversos modelos psicoacústicos, alguns dos quais serão utilizados no presente trabalho. 



\section{Parte I}

Fundamentação Teórica e Revisão Bibliográfica 



\section{A Orelha Humana}

O órgão da orelha, também chamado de ouvido, é dividido em orelha externa, orelha média e orelha interna. A cóclea, órgão no interior da qual encontra-se a membrana basilar, é localizada na orelha interna, é o principal foco do presente trabalho.

A figura 1 ilustra a orelha humana e suas principais partes. A orelha externa corresponde aos números 1 a 3 , a orelha média aos números 4 a 8 e a orelha interna aos números 9 a 12 .

Serão apresentadas breves descrições anatômicas e fisiológicas de cada segmento da orelha a fim de se aprofundar a compreensão do aparelho auditivo.

\subsection{Orelha Externa}

A orelha externa, constituída pelo pavilhão auricular e pelo conduto auditivo externo, ou meato acústico externo, é responsável pela captação do som, e tem como limite interno a membrana timpânica.

O pavilhão auricular é formado por um esqueleto cartilaginoso, um aparelho músculoligamentar e revestimento cutâneo, que contém pelos e glândulas sebáceas e sudoríparas (BENTO; MINITI; MARONE, 1998).

O meato acústico externo também apresenta um revestimento cutâneo contínuo,

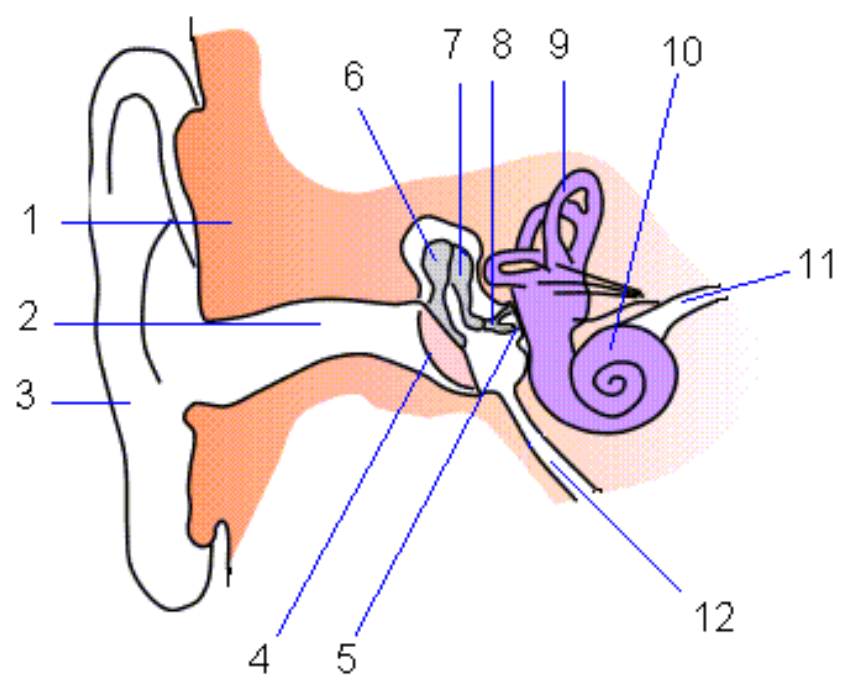

Figura 1: Ilustração esquemática da orelha humana. 1. Crânio; 2. Canal auditivo; 3. Pavilhão Auricular; 4. Membrana timpânica; 5. Janela oval; 6. Martelo; 7. Bigorna; 8. Estribo; 9. Labirinto; 10. Cóclea; 11. Nervo auditivo; 12. Tubo de Eustáquio. Retirado de Wikimedia Commons (WIKIMEDIA, 2013). 
que contém pelos e glândulas sebáceas e sudoríparas, que é mais denso no orifício externo e afina-se progressivamente até o limite com a membrana timpânica, onde torna-se uma simples camada epidérmica. Ele possui cerca de $31 \mathrm{~mm}$ de comprimento em sua parede ântero-inferior (BENTO; MINITI; MARONE, 1998). As propriedades físicas do meato acústico foram detalhadamente estudadas por Couto (COUTO, 2000), que calculou e mediu experimentalmente as variações da pressão sonora ao longo de seu eixo central.

Em indivíduos saudáveis, o revestimento cutâneo do meato acústico externo é coberto por um filme lipídico que apresenta propriedades antibacterianas e fungistáticas, além de prevenir macerações da pele.

O pavilhão auricular e o meato acústico são irrigados por ramos das artérias temporais, e os músculos do pavilhão são inervados pelo nervo facial (BENTO; MINITI; MARONE, 1998).

\subsection{Orelha Média}

A função fundamental da orelha média é resolver a incompatibilidade de impedância acústica entre o ar na orelha externa e os fluidos da orelha interna, função sem a qual muito pouca energia sonora seria transmitida à cóclea. (FAY et al., 2005).

A transmissão do som através dos ossículos da orelha média é conhecido como "rota ossicular", enquanto a transmissão na orelha interna é chamada de "rota acústica"(VOSS et al., 2007).

A orelha média separa-se do meato acústico pela membrana timpânica e da orelha interna pelas janelas oval (também chamada de janela vestibular) e redonda (também chamada de janela coclear).

Ela é constituída pela membrana timpânica, pela cavidade timpânica - que é preenchida com ar e se comunica através da trompa de Eustáquio com a rinofaringe -, pelo antro mastoideo, pelas células mastóideas e pela trompa de Eustáquio,também chamada de tuba auditiva.

A cavidade timpânica, de localização central no osso temporal, possui formato cilíndrico, sendo as bases formadas pela membrana timpânica e pela parede lateral do labirinto, e abriga uma cadeia de três ossículos - martelo, bigorna e estribo - que transmite os efeitos vibracionais das ondas sonoras que atingem a membrana timpânica para a janela oval e, consequentemente, para os líquidos da orelha interna. A membrana timpânica tem área de aproximadamente $65 \mathrm{~mm}^{2}$ e formato côncavo devido à tração que o cabo do martelo exerce. (BENTO; MINITI; MARONE, 1998).

As propriedades reflexivas da membrana timpânica, assim como toda a estrutura mecânica da orelha, funcionam como uma espécie de filtro auditivo, permitindo em di- 
ferentes proporções a propagação de sons em diferentes faixas de frequência (STINSON, 1990), conforme será discutido posteriormente.

Os ossículos móveis formam uma cadeia através da cavidade timpânica, conectando a membrana timpânica, onde está inserido o martelo, à janela oval, onde encontra-se fixado o estribo. O ossículo intermediário, chamado de bigorna, permanece articulado entre os dois demais. A orelha média possui dois músculos, o músculo tensor do tímpano, que traciona o cabo do martelo de forma a enrijecer a membrana timpânica, e o músculo do estribo, que traciona lateralmente uma das bordas do estribo. (BENTO; MINITI; MARONE, 1998). Os ossículos e a membrana timpânica foram detalhadamente modeladas utilizando-se o método dos elementos finitos em (HU et al., 2017).

\subsection{Orelha Interna}

A orelha interna é constituída pelo labirinto membranoso (ou labirinto endolinfático), pelo labirinto ósseo (ou labirinto perilinfático) e pela cápsula ótica envolvente (BENTO; MINITI; MARONE, 1998).

O labirinto membranoso, preenchido pela endolinfa (fluido de Scarpa), fluido de densidade e viscosidade iguais às da água, é envolvido pelo labirinto ósseo, e contém o ducto coclear, o utrículo e três canais circulares. O ducto coclear é um tubo epitelial de forma espiral - acoplado sobre a cóclea óssea e cuja espiral forma duas voltas e meia - cujo assoalho é formado parcialmente por um periósteo que recobre a periferia da lâmina espiral óssea. Já o labirinto ósseo é constituído pelos canais semicirculares (labirinto posterior), vestíbulo (labirinto médio) e a cóclea, e é preenchido pela perilinfa, que é um filtrado do sangue.

A cóclea possui $9 \mathrm{~mm}$ de largura e $5 \mathrm{~mm}$ de comprimento axial. O canal espiral possui aproximadamente $30 \mathrm{~mm}$ de comprimento e é dividido em uma passagem superior (escala vestibular) e uma inferior (escala timpânica) (BENTO; MINITI; MARONE, 1998).

\subsection{Cóclea, Membrana Basilar e Órgão de Corti}

A cóclea possui formato de uma concha de caracol, característica que não apresenta qualquer significância funcional além da ocupação de menos espaço, e apresenta paredes rígidas. Ela é preenchida por fluidos quase incompressíveis e é dividida ao longo de seu comprimento pela membrana de Reissner e pela membrana basilar (MOORE, 2012). O tamanho da cóclea não muda entre o nascimento e avida adulta de indivíduos humanos (PELLICCIA et al., 2014).

No interior da cóclea encontra-se a membrana basilar, que ocupa menos de $15 \%$ da largura do canal coclear durante quase toda a sua extensão (BOER, 1980). A membrana 


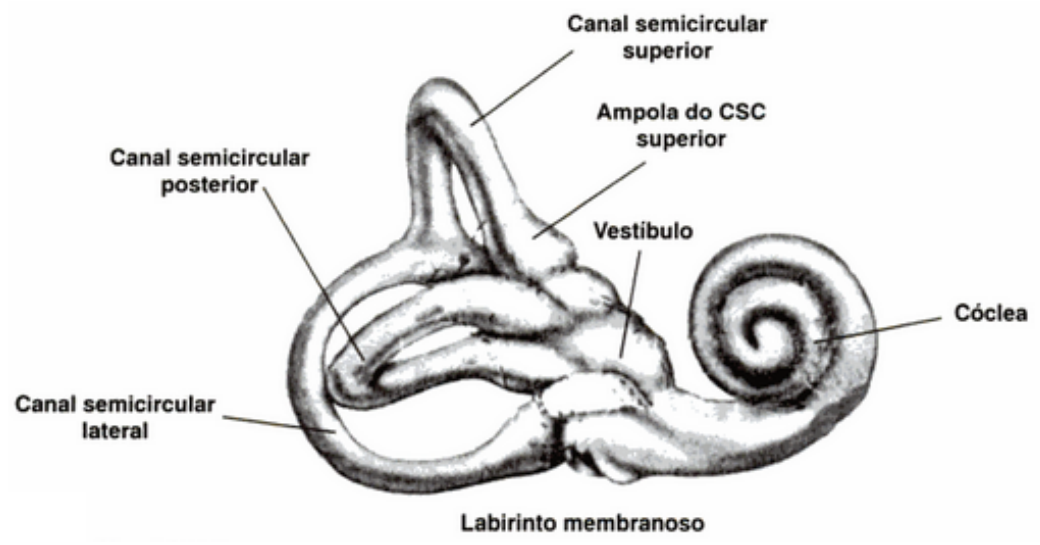

Figura 2: Ilustração do bloco labiríntico. Reproduzido de Bento et al. (BENTO; MINITI; MARONE, 1998) com autorização do autor.

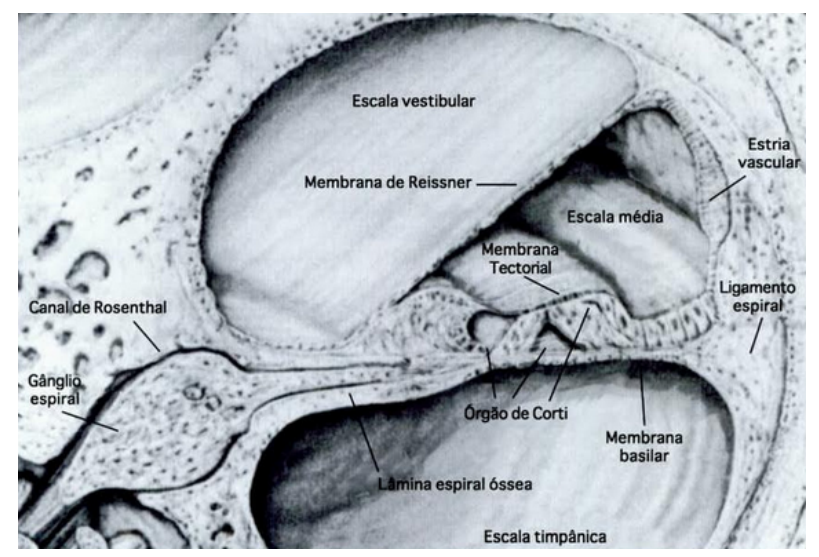

Figura 3: Imagem de corte da cóclea. Reproduzido de Bento et al. (BENTO; MINITI; MARONE, 1998) com autorização do autor.

basilar possui tecido fibroso e se estende da borda livre da lâmina espiral até o periósteo que reveste a periferia do canal ósseo da cóclea. O assoalho da cóclea é formado por um tecido altamente especializado que forma também o órgão espiral de Corti, ao qual fibras do nervo coclear são ligadas (BENTO; MINITI; MARONE, 1998). A figura 3 ilustra uma seção de uma cóclea, e a figura 4 ilustra uma reconstrução da cóclea humana feita a partir de materiais siliconados.

Em uma das pontas da cóclea encontra-se a janela oval, em contato com a orelha média, e esta região é chamada de base, região na qual a membrana basilar tem aproximadamente $0.1 \mathrm{~mm}$, enquanto a outra ponta é chamada de ápice, em que ela tem aproximadamente 0.5mm (BÉKÉSY; WEVER, 1960). No ápice há uma pequena abertura chamada de helicotrema, localizada entre a membrana basilar e a parede da cóclea, que conecta a rampa timpânica e a rampa vestibular. Também há uma abertura na cóclea chamada janela redonda, e movimentos para dentro da janela oval, causados pelo movimento do estribo, resultam em movimentos para fora na janela redonda (MOORE, 2012). 


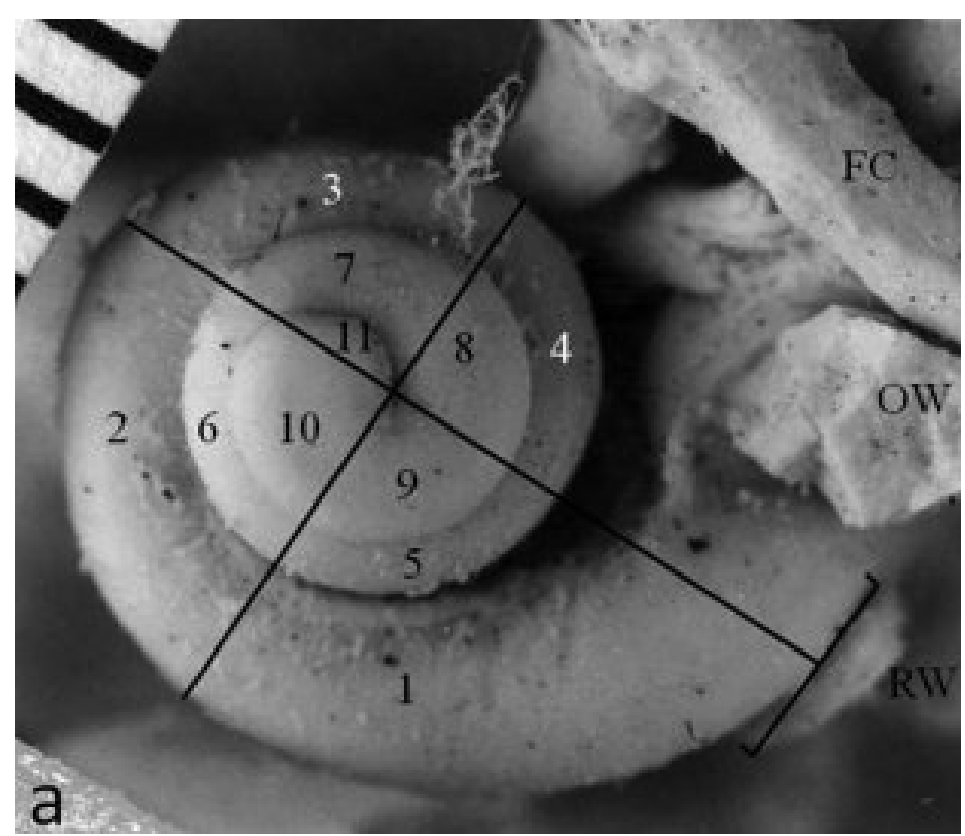

Figura 4: Reconstrução de uma cóclea. Reproduzido de Rask-Andersen et al. (RASK-ANDERSEN et al., 2012).

O estímulo acústico na cóclea é essencialmente dado pela diferença de pressão entre as janelas oval e redonda (VOSS; ROSOWSKI; PEAKE, 1996). Quando a janela oval se movimenta, uma diferença de pressão é aplicada à membrana basilar, localizada no interior da cóclea, que responde de forma diferente para cada frequência. No caso de estímulos sinusoidais (tons puros), a membrana responde na forma de uma onda que é transmitida do da base ao ápice, cujo ponto de máxima amplitude é condicionado à frequência do estímulo sinusoidal.

As frequências mais altas produzem máximo deslocamento na base da membrana, próxima ao estribo, que é mais estreita e rígida, enquanto frequências mais baixas provocam máximo deslocamento no ápice, que é mais largo e menos rígido (MOORE, 2012). Desta forma, para sons complexos - sons compostos por várias frequências - diferentes regiões da membrana são estimuladas, de forma que a membrana basilar realiza uma espécie de "análise de Fourier", analogia sugerida pela primeira vez por Helmholtz (HELMHOLTZ, 1954).

Um estudo detalhado da resposta da membrana basilar em função da frequência e no nível de pressão sonora em diferentes mamíferos foi publicado por Robles e Ruggero (ROBLES; RUGGERO, 2001). Estudos do comportamento vibratório da membrana basilar já foram desenvolvidos tanto em membranas de cadáveres, como é o caso de alguns dos estudos realizados por Békésy (BÉKÉSY; WEVER, 1960) ou in vivo utilizando técnicas de laser como o Mössbauer (RUGGERO; RICH, 1991b) ou interferometria (KHANNA; LEONARD, 1986). Também utilizando o método dos elementos finitos, Skrodzka (SKRODZKA, 2005) modelou o comportamento da membrana basilar. 


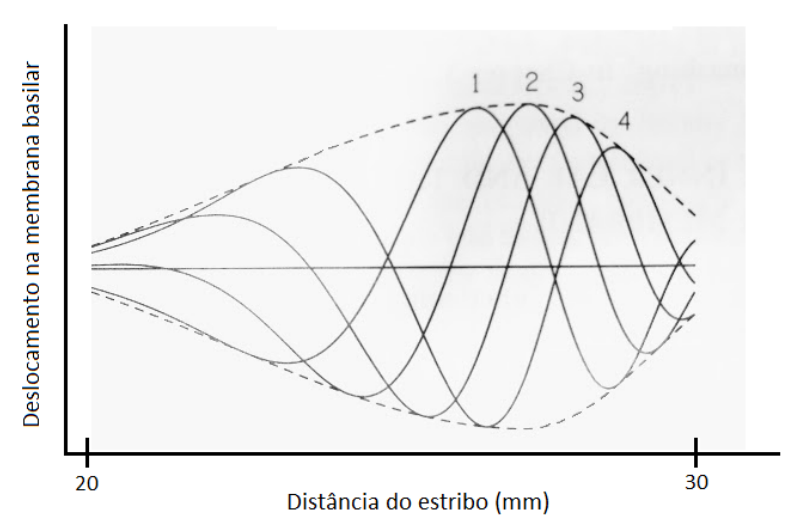

Figura 5: Esquema ilustrativo do deslocamento da membrana basilar em quatro momentos consecutivos, da esquerda para a direita. A linha tracejada indica o envelope formado pelos picos de amplitude. Adaptado de Moore (MOORE, 2012).

Borsboom argumenta, analítica e numericamente, que os comportamentos nãolineares na movimentação da membrana basilar, que não serão discutidos no presente trabalho, estão associados não à variação na elasticidade ao longo da membrana, mas a processo mais complexos no órgão de Corti (BORSBOOM; VIERGEVER, 1980).

A figura 5 ilustra o comportamento da membrana basilar em resposta a um tom puro em quatro momentos consecutivos.

Entre a membrana basilar e a membrana tectorial encontra-se o órgão de Corti. O órgão é formado por um tecido altamente especializado e constitui uma elevação sobre a membrana basilar que se estende por todo o ducto coclear. Ele é formado por células de sustentação, que se estendem da membrana basilar até a superfície livre, e por dois grupos de células ciliadas, externas e internas, de formato cilíndrico e cuja base permanece em contato com a membrana basilar (BENTO; MINITI; MARONE, 1998). A figura 6 ilustra as células ciliadas do órgão de Corti. As células ciliadas externas são as responsáveis pela alta seletividade das respostas cocleares a excitações causadas por sons de níveis de pressão sonora mais baixos (COUTO, 2004).

Gold (GOLD, 1948) introduziu o conceito de emissão otoacústica, que são sons produzidos pelas células ciliadas externas, passando pela orelha média percorrendo o caminho inverso das ondas sonoras até o meato acústico externo. Essa hipótese foi comprovada por Kemp em 1978 (COUTO, 2004).

O órgão de Corti conecta-se ao nervo cócleo-vestibular, que por sua vez conduz o sinal para o cérebro. O órgão divide-se em duas partes, uma localizada no fundo do meato acústico interno e uma no canal espiral, alcançando as células ciliadas do órgão de Corti (BENTO; MINITI; MARONE, 1998).

O fluxo de informação entre a orelha interna e o cérebro passa por aproximadamente 30 mil fibras nervosas, que se diferenciam em termos de atividade elétrica espontâ- 


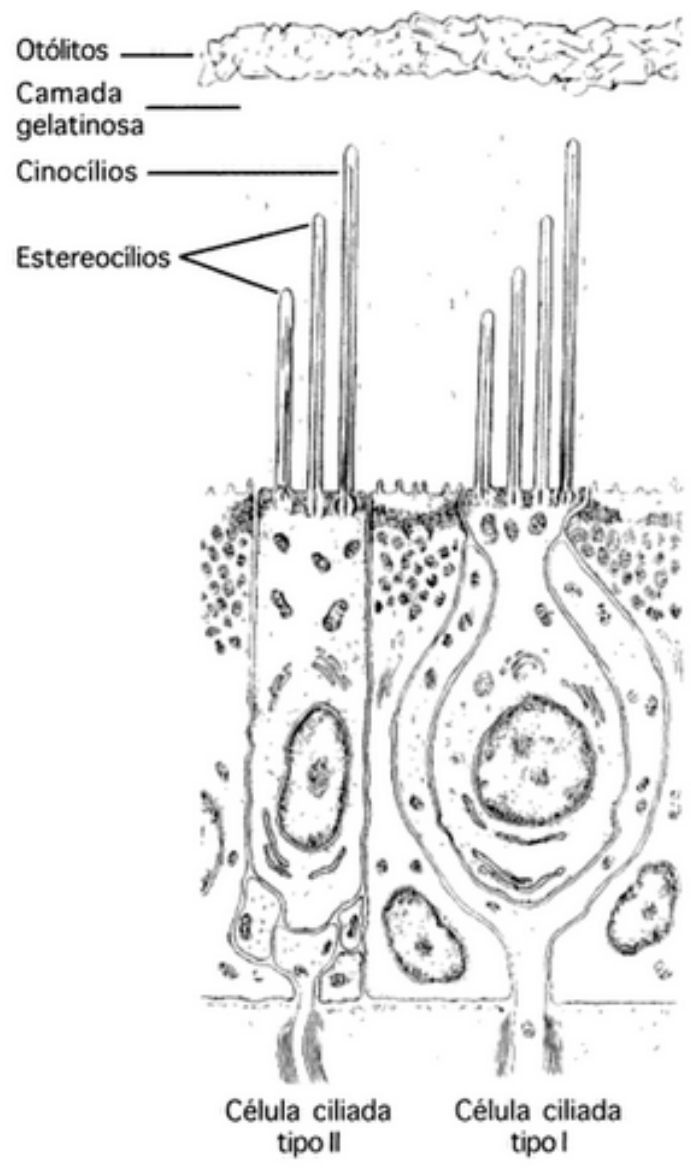

Figura 6: Esquema das células ciliadas. Sobre os cílios existe uma camada gelatinosa que contém granulações calcárias denominadas oto-cônicas. Reproduzido de Bento et al. (BENTO; MINITI; MARONE, 1998) com autorização do autor.

nea e resposta a frequências diferentes. A distribuição de frequências que ocorre na cóclea é preservada nestas fibras, de forma que a frequência característica de cada fibra é determinada pela parte correspondente da membrana basilar à qual a inervação conecta-se.

As fibras nervosas tendem a manter sua relação espacial entre si, resultando em um arranjo sistemático de resposta a frequência conhecido como tonotopia(ZWICKER; FASTL, 2013). 



\section{Conceitos de Acústica e Psicoacústica}

Os parâmetros físicos do som, como frequências, composição espectral, durações e tempos de reverberação, podem ser medidos através de instrumentos convencionais de medições físicas como microfones, osciloscópios e analisadores de espectros.

Já os parâmetros relacionados à percepção auditiva, como percepção de altura, percepção de duração, timbre, rugosidade, dissonância e volume (loudness), que são condicionados ao processamento do sinal no sistema auditivo e no sistema nervoso, são calculados a partir de testes subjetivos realizados com voluntários, e não se relacionam de forma linear com os parâmetros físicos correspondentes (KINSLER et al., 1982).

A seguir, são apresentados os fundamentos da acústica da audição humana e da psicoacústica que serão discutidos neste trabalho.

\subsection{Cálculo da Distribuição da Pressão Sonora na Cóclea}

A distribuição da pressão sonora no meato acústico externo foi detalhadamente estudada por Couto (COUTO, 2000), que desenvolveu com sucesso um método de previsão teórica da distribuição da pressão sonora e da impedância ao longo do meato acústico externo a partir dos trabalhos de Helmholtz (HELMHOLTZ, 1954) e Stinson (STINSON, 1985).

O mesmo método é aplicado no presente trabalho para o cálculo da distribuição da pressão sonora na cóclea ao longo do eixo central que vai desde a base até o ápice da cóclea desenrolada, através de algumas simplificações.

Desta forma, novos parâmetros devem ser introduzidos, tendo em vista que a geometria da cóclea difere tanto com relação às dimensões consideravelmente menores quanto com relação às áreas das sucessivas secções transversais. Os meios de propagação também passam a ser os líquidos cocleares, de densidade igual à da água (BENTO; MINITI; MARONE, 1998), o que afeta a velocidade de propagação do som.

Os novos valores dos parâmetros avaliados com base nas informações disponíveis na literatura, passam a ser $v_{s} \approx 1500 \mathrm{~m} / \mathrm{s}$ (velocidade do som na água) e $\rho_{0} \approx 10^{3} \mathrm{~kg} / \mathrm{m}^{3}$ (densidade da água).

Seja $\omega=2 \pi f$ a velocidade angular, temos que o número de onda é dado por $k=\omega / v_{s}=2 \pi / \lambda$.

Adotamos as simplificações que já foram utilizadas para a equação de onda de Helmholtz original, inclusive substituindo a trajetória curvilínea $s$ por uma trajetória reti- 
línea ao longo de um eixo $x$, mantendo os comprimentos dos segmentos iguais e utilizandose o sistema MKS de unidades. A equação 3.1 é utilizada no cálculo da pressão sonora. Os detalhes de toda a demonstração são acessíveis em Couto (COUTO, 2000) e não serão aqui repetidos.

$$
\frac{d}{d x}\left(A \frac{d p}{d x}\right)+k^{2} A p=0
$$

Couto também debate a impedância sonora, que depende diretamente de $\frac{d p}{d x}$, conforme mostra a equação 3.2 .

$$
Z(x)=\frac{p(x)}{u(x)}
$$

Em que a velocidade $u(x)$ do volume do fluido é dada por

$$
|u(x)|=\frac{A(x)}{\omega \rho_{0}} \frac{d p}{d x}
$$

\subsection{Contribuições de Helmholtz}

O físico, médico e matemático alemão Hermann Ludwig Ferdinand von Helmholtz dedicou-se exaustivamente ao estudo da acústica e da fisiologia da audição, bem como suas relações com os conceitos de consonância e dissonância musicais. Helmholtz argumenta que as sensações de consonância e dissonância são causadas não apenas pela interação entre os parciais de tons escutados, mas também à maneira como estas interações afetam a fisiologia do ouvido (SILVA, 2017).

Helmholtz observa e demonstra, em sua obra "On the Sensations of Tone as a Physiological Basis for the Theory of Music"(HELMHOLTZ, 1954) a equivalência espacial entre a posição na membrana basilar e as frequências correspondentes, traçando uma analogia com o trabalho do matemático Jean Baptiste Fourier, que já havia demonstrado que qualquer função periódica poderia ser representada como uma soma de funções senoidais ponderadas através de amplitudes.

Desta forma, o ouvido seria capaz de analisar separadamente todas as componentes de um estímulo sonoro, conceito a partir do qual concebeu os conceitos de consonância e dissonância como respostas sensoriais intrínsecas à constituição do aparato auditivo (SILVA, 2017). Para Helmholtz, intervalos musicais consonantes seriam aqueles em que todos ou muitos dos parciais superiores de dois tons coincidem. Quando tais parciais são harmônicos da fundamental, os intervalos consonantes seriam aqueles em que a razão entre as frequências fundamentais das notas pode ser representada por uma fração com 
numeradores e denominadores inteiros e pequenos, como 1:2 (oitava), 2:3 (quinta), 3:4 (quarta), 4:5 (terça maior) e 5:6 (terça menor) (PIERCE, 1966).

Em 1965, Plomp e Levelt ampliaram este conceito, propondo que um intervalo entre dois tons puros é consonante quando nenhum de seus parciais correspondem à mesma banda crítica (PLOMP; LEVELT, 1965), conceito que será detalhado em seguida. Desta forma, sons complexos podem ser classificados em uma escala contínua de dissonância ou de consonância de acordo com seus parciais.

\subsection{Contribuições de Békésy}

O biofísico húngaro Georg von Békésy, que recebeu o prêmio Nobel de Fisiologia ou Medicina de 1961 pelo seu trabalho com a cóclea, dedicou-se exaustivamente à realização de experimentos em orelhas humanas e animais, criticando trabalhos anteriores pois, segundo ele, "dificilmente existia qualquer fenômeno psicológico ou observação clínica que não tivesse sido usado como base para conclusões sobre o padrão de ação da cóclea [...] não havia restrições para a imaginação". Para ele, a única forma de resolver o problema seria examinar a cóclea aberta e vê-la em ação. Békésy é também provavelmente o primeiro cientista a revisitar de forma robusta do trabalho de Helmholtz sobre audição(PURIA; ROSOWSKI, 2012; BÉKÉSY; WEVER, 1960). Békésy dedicou-se também ao estudo de fenômenos que ocorrem orelha média, dentre os quais o efeito da perfuração da membrana timpânica na transmissão do som para a orelha interna e o atraso que a estrutura da orelha média oferece na transmissão de frequências acima de $1 k H z$ (PURIA; ROSOWSKI, 2012) em diversos mamíferos, efeito até hoje sob investigação em roedores (ROCHEFOUCAULD et al., 2008).

O biofísico também mapeou o deslocamento na membrana timpânica em cadáveres - as propriedades mecânicas passivas dos tecidos não sofrem alterações consideráveis contanto que a hidratação dos mesmos seja mantida -, e seu mapeamento tem sido revisto na literatura através da realização de experimentos in vivo com utilização lasers. A figura 7 mostra um exemplo comparativo do mapeamento do deslocamento induzido por estímulos sonoros na membrana timpânica realizado por Békésy e por autores posteriores (PURIA; ROSOWSKI, 2012; TONNDORF; KHANNA, 1972).

Békésy também foi pioneiro no estudo da diferença entre a transmissão o som que atinge a orelha interna através do ar, passando pelas orelhas externa e média, e através dos ossos da caixa craniana, diferença a qual é um dos fatores responsáveis pelo fato de humanos e outros mamíferos escutarem de formas diferentes os sons provenientes do ambiente e os sons gerados pelo próprio organismo (PURIA; ROSOWSKI, 2012).

Seus experimentos com a cóclea também resultaram na equação 3.4, que relaciona a frequência $f$ com a posição na membrana basilar $(x$, em $m$, convencionando-se 0 como o 


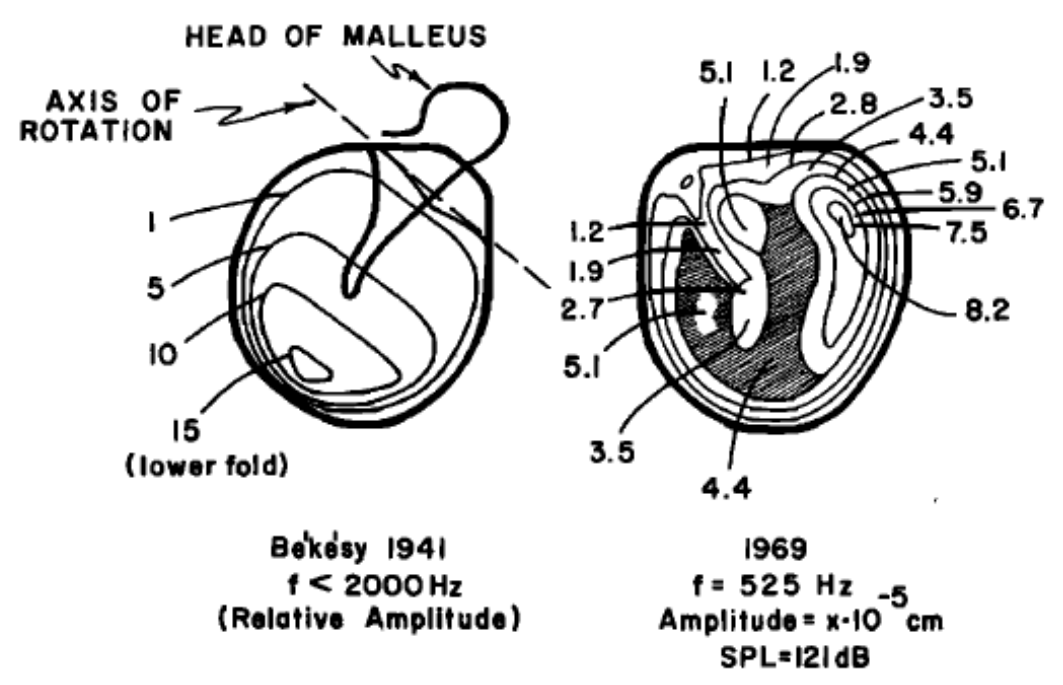

Figura 7: Comparação entre modelos de deslocamento induzido na membrana timpânica. Reproduzido de Purial \& Rosowski (PURIA; ROSOWSKI, 2012), adaptado de Tonndorf \& Khanna (TONNDORF; KHANNA, 1972)

ponto em que se encontra o estribo) cujo pico de amplitude corresponde a tal frequência. Esta equação é válida apenas para frequências acima de 200Hz (KINSLER et al., 1982).

$$
f=2.5 \times 10^{4-72 x}
$$

\subsection{Breve Discussão sobre o Timbre}

Uma das características do som que só pode ser determinada a partir de testes subjetivos é o timbre, que apesar de dialogar com grandezas que podem ser medidas fisicamente, é uma característica que envolve aspectos perceptivos e cuja definição não é consenso na literatura.

A fim de se estudar a percepção de timbre, vários modelos psicoacústicos foram propostos nas últimas décadas. Entende-se que o timbre é um conjunto de vários atributos auditivos, e portanto modelagens multi-dimensionais se fazem necessárias.

McAdams (MCADAMS, 2013) argumenta que tal modelagem deve levar em conta a composição espectral do som, ou seja, quais frequências fazem parte de determinada nota e as proporções entre as amplitudes destas frequências, o fluxo espectral, ou seja, a forma como a composição espectral varia ao longo do tempo durante a execução de uma nota e o tempo de ataque, que é o tempo entre o início da execução de um som até a identificação do mesmo, que varia consideravelmente entre um instrumento e outro. As batidas percussivas, por exemplo, possuem um tempo de ataque inferior ao tempo de ataque das notas executadas por um violino (MCADAMS, 2013). 
Tais modelagens são bastante úteis na síntese sonora utilizada em instrumentos musicais eletrônicos, além de trazer pistas sobre o processamento da música no cérebro(THORET; DEPALLE; MCADAMS, 2017), ramo da neurociência que tem demonstrado cada vez mais ser extremamente complexo. 



\section{Propriedades Psicoacústicas da Cóclea}

\subsection{Mascaramento e Bandas Críticas}

Mascaramento é o deslocamento do limiar de audibilidade de um determinado tom pela presença de outros tons, causado pela interferência do deslocamento da membrana basilar na análise do tom mascarado (KINSLER et al., 1982). O mascaramento é responsável por alguns fenômenos de ilusões aurais, dentre as quais as ilusões de agrupamento (HOWARD; ANGUS, 2009).

As bandas críticas são bandas de frequências dentro das quais dois tons tocados simultaneamente causam mascaramento na membrana basilar (HARTMANN, 2004).

Tal conceito foi introduzido por Harvey Fletcher em 1937, e visava estabelecer uma relação de "coordenadas de posição"na membrana basilar de forma a dividir o espectro de frequência em partes igualmente eficientes em termos de mascaramento do som, tendo observado que tais partes possuíam tamanhos diferentes de acordo com a faixa de frequência (ZWICKER; FLOTTORP; STEVENS, 1957).

Tais bandas possuem extensões diferentes de acordo com a faixa de frequências, mas são em geral mais estreitas que um terço de oitava, e cada uma delas é representada por um número, representado por $z$.

Podemos definir a variação em $z$ em função da variação da frequência $f$ é dada por

$$
d z=\frac{\Delta z}{\Delta f} d f
$$

Definindo a banda crítica $B(f)$ como a mudança necessária na frequência para mudar as unidades de banda crítica, temos que

$$
d z=\frac{1}{B(f)} d f
$$

Portanto, convencionando-se a banda crítica zero como equivalente à frequência zero, temos

$$
z(f)=\int_{0}^{f} \frac{1}{B\left(f^{\prime}\right)} d f^{\prime}
$$

Alguns modelos de banda crítica já foram elaborados desde o trabalho de Fletcher. Focaremos nos modelos conhecidos como "bandas críticas de Cambridge"e "bandas críticas 
de Munique". Ambas representam bandas críticas retangulares equivalentes (equivalent rectangular bandwidths ou ERBs, em inglês, modelo de filtro auditivo simplificado por um filtro passa-banda retangular idealizado) e derivam de experimentos de mascaramento realizados com voluntários. O comportamento das bandas críticas acima dos $10 \mathrm{kHz}$ é dificilmente determinado (HARTMANN, 2004).

A bandas críticas de Cambridge são definidas em função da frequência central $F$ da banda, em $k H z$ como

$$
B_{C}=24.7(1+4.37 F)
$$

A equação 4.3, utilizando-se $H z$ como unidade de frequência fica portanto

$$
z(f)=\int_{0}^{f} \frac{1}{24.7\left(1+0.00437 f^{\prime}\right)} d f^{\prime}
$$

Resolvendo-se a integral

$$
z(f)=\left[\frac{1}{24.7} \frac{1}{0.00437} \ln \left(1+0.00437 f^{\prime}\right)\right]_{0}^{f}
$$

Portanto

$$
z(f)=\frac{1}{24.7} \frac{1}{0.00437} \ln (1+0.00437 f) \approx 9,26 \ln (1+0.00437 f)
$$

Convencionando-se o uso do logaritmo comum, temos

$$
z(f) \approx 21.33 \log (1+0.00437 f)
$$

Zwicker foi o responsável pela crianção das "bandas críticas de Munique", anterior às de Cambridge mas ainda um dos mais frequentemente utilizado em trabalhos de psicoacústica, que introduz a unidade Bark de número de banda crítica (HARTMANN, 2004). A tabela que define tais bandas críticas é reproduzida de (ZWICKER, 1961) no Apêndice A. A banda crítica número 0 é novamente associada a $f=0$. Se a diferença do número de banda crítica entre duas frequências for inferior a 1 Bark tais frequências pertencem à mesma banda crítica.

A figura 8 ilustra a distribuição das bandas críticas conforme definidas por Zwicker.

A escala Bark não possui expressão analítica, mas Traunmüller (TRAUNMÜLLER, 1990) propôs uma série de equações para converter frequências $(f)$ em número de banda crítica $(z)$, conforme indicam as equações 4.9 a 4.12 (HARTMANN, 2004). 


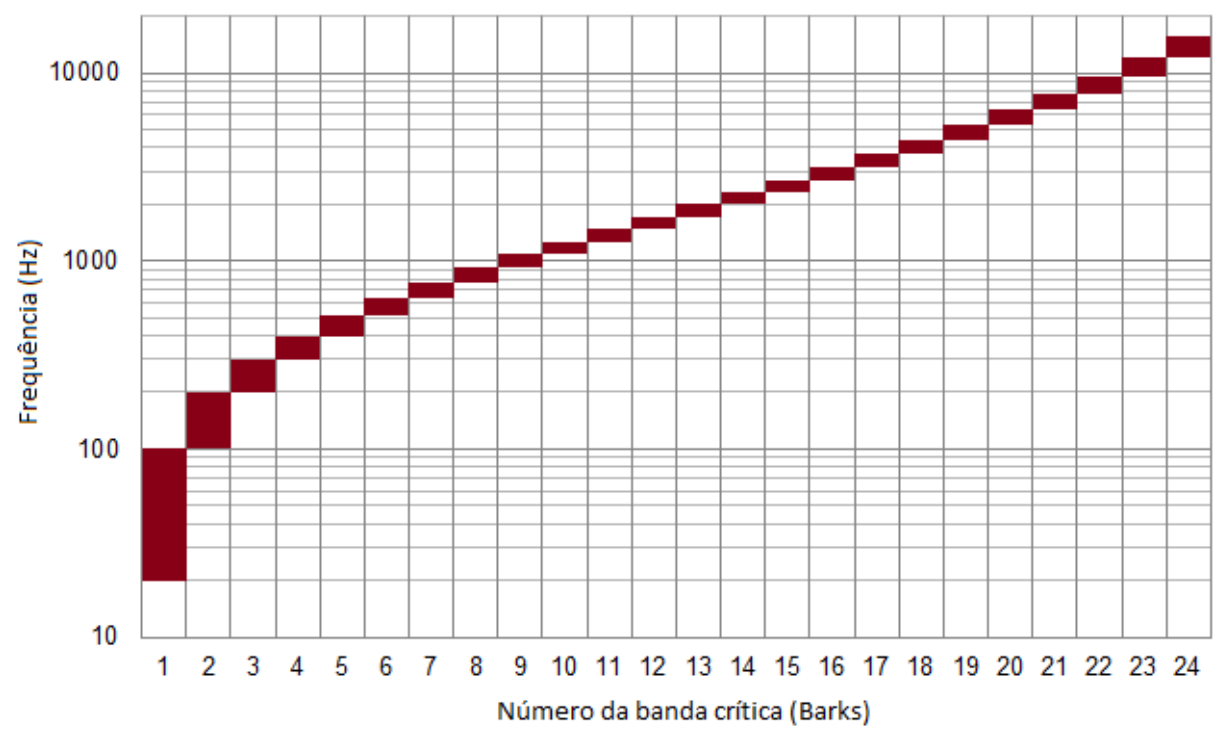

Figura 8: Representação gráfica da escala de Barks proposta por Zwicker. O eixo horizontal representa o número da banda e o eixo vertical, em escala logarítmica, indica as frequências correspondentes. Adaptado de Wiki Media Commons (WIKIMEDIA, 2016).

$$
z^{\prime}=\frac{26.81 f}{1960+f}-0.53
$$

Se $z^{\prime}<2.0$ Bark, então

$$
z=z^{\prime}+0.15\left(2.0-z^{\prime}\right)
$$

Se $z^{\prime}>20.1$ Bark, então

$$
z=z^{\prime}+0.22\left(z^{\prime}-20.1\right)
$$

Caso contrário

$$
z=z^{\prime}
$$

A figura 9 ilustra a equivalência entre a escala Bark, a frequência e a posição na membrana basilar, convencionando-a como a distância com relação à janela redonda.

\subsection{Combinações de Tons, Batimentos e Rugosidade}

Dados dois tons puros de frequências $f_{1}$ e $f_{1}$, de mesma amplitude, a percepção de tais tons executados simultaneamente está condicionada à sua diferença, como já foi brevemente discutido na seção sobre Helmholtz.

Quando esta diferença é muito pequena, o som é percebido como um tom cuja frequência é $f_{C}=\left(f_{1}+f_{2}\right) / 2$ e cuja intensidade flutua à frequência de batimento $f_{B}=$ 

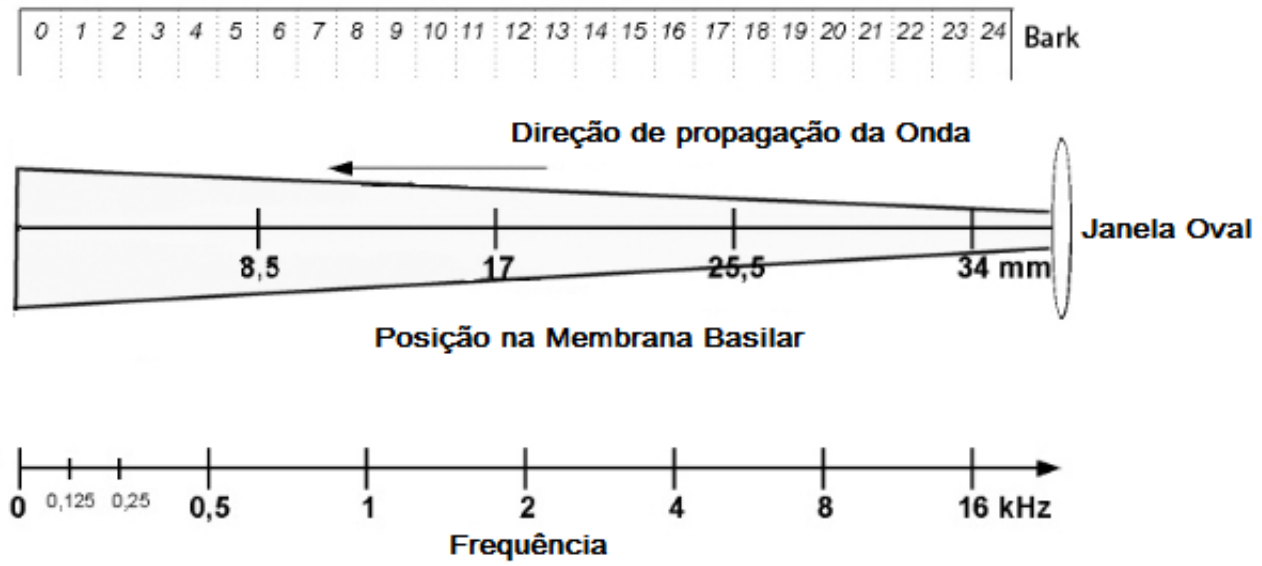

Figura 9: Relação entre posição na membrana basilar ( $\mathrm{mm})$, bandas críticas (Bark) e frequência (Hz). Adaptado de The Speech Recognition Wiki (MAIOLO, 2015).

$\left|f_{1}-f_{2}\right|$. Conforme o intervalo aumenta, o som é então percebido como uma vibração (quando a diferença é de aproximadamente $5 \mathrm{~Hz}$ a $10 \mathrm{~Hz}$, para frequências médias) e então como "rugoso"(diferença de aproximadamente $15 \mathrm{~Hz}$ a $30 \mathrm{~Hz}$, para frequências médias), até que a sensação de rugosidade se dissipa e o som passa a ser interpretado como dois tons distintos.

Tais efeitos ocorrem apenas quando os dois tons são emitidos para a mesma orelha ou para ambas as orelhas simultaneamente, e não quando cada tom é emitido para orelhas diferentes, evidenciando a relação entre o fenômeno da rugosidade com a mecânica da membrana basilar (KINSLER et al., 1982).

A rugosidade é medida através de testes subjetivos, e é normalmente representada através da unidade asper. Convenciona-se como 1asper a sensação de rugosidade causada por um tom puro de $1 k H$ modulado a $70 H z$ (DANIEL, 2008). A rugosidade está intimamente ligada ao conceito de dissonância sensorial.

\subsection{Dissonância Sensorial}

Dentre diversas definições de dissonância, que podem levar em consideração aspectos culturais e cognitivos, a dissonância sensorial é aquela relacionada estritamente ao fenômeno da rugosidade, conforme proposto inicialmente por Helmholtz (HELMHOLTZ, 1954) e desenvolvido por Plomp e Levelt (PLOMP; LEVELT, 1965) que, através de experimentos com voluntários sem treinamento musical, desenvolveram as primeiras curvas de dissonância sensorial.

Dando continuidade ao trabalho de Plomp e Levelt, Sethares desenvolveu o modelo de dissonância sensorial provocada por dois tons puros, dada pelas equações 4.13 a 4.15, 
demonstradas em seu livro "Tuning, timbre, spectrum, scale"(SETHARES, 2005b). Nas equações, a função de dissonância é representada por $d$, as frequências de dois tons puros por $f_{1}$ e $f_{2}$, a grandeza "loudness"associada aos tons puros representada representada respectivamente por $l_{1}$ e $l_{2}$. Os demais parâmetros são definidos como $x^{*}=0.24, b_{1}=3.5$, $b_{2}=5.75, s_{1}=0.0207$ e $s_{2}=18.96$.

$$
\begin{gathered}
\left.d\left(f_{1}, f_{2}, l_{1}, l_{2}\right)=l_{12}\left[e^{-b_{1} s\left(f_{2}-f_{1}\right)}-e^{-b_{2} s\left(f_{2}-f_{1}\right.}\right)\right] \\
s=\frac{x^{*}}{s_{1} f_{1}+s_{2}} \\
l_{12}=\min \left(l_{1}, l_{2}\right)
\end{gathered}
$$

A equação 4.16 representa a função de dissonância para múltiplos pares de tons.

$$
D_{F}=\frac{1}{2} \sum_{i=1}^{n} \sum_{j=1}^{n} d\left(f_{i}, f_{j}, l_{i}, l_{j}\right)
$$

O modelo de dissonância sensorial foi revisado por Vassilakis, que define a função de dissonância de acordo com a equação 4.17, em que os parâmetros $x^{*}, b_{1}, b_{2}, s_{1}$ e $s_{2}$ e a grandeza $s$ são mantidos. (VASSILAKIS, 2001).

$$
d\left(f_{1}, f_{2}, l_{1}, l_{2}\right)=0.5\left(l_{1} l_{2}\right)^{0.1} \frac{2 l_{2}}{l_{1}+l_{2}}\left[e^{-b_{1} s\left(f_{2}-f_{1}\right)}-e^{-b_{2} s\left(f_{2}-f_{1}\right)}\right]
$$

Este modelo de dissonância sensorial foi aplicado em (SILVA; FARIA; BAYEH, 2017) e (SILVA; BAYEH; FARIA, 2017), conforme será descrito posteriormente. 

Parte II

Aplicações 



\section{Materiais e Métodos}

Os conceitos desenvolvidos nos capítulos anteriores serviram como base para aplicações matemáticas e computacionais que serão divididas em duas partes: O cálculo da distribuição da pressão sonora na cóclea a partir do trabalho de Couto (COUTO, 2000) e o desenvolvimento de um algoritmo para filtragem de espectros a partir dos modelos de banda crítica de Munique e Cambridge.

\subsection{Cálculo da Distribuição da Pressão Sonora na Cóclea}

As dimensões detalhadas do interior da cóclea e a avaliação aproximada dos raios $r$ e áreas $A$ das sucessivas secções transversais foram deduzidas a partir da imagem fotográfica de uma réplica de cóclea exibida na figura 4 e sua respectiva escala.

O segmentos da cóclea utilizados para cálculo das áreas das secções transversais correspondentes, aproximadas para secções circulares, de forma que $A=\pi r^{2}$, foram distribuídos em intervalos de comprimento $l=1.57 \mathrm{~mm}$, conforme ilustra a figura 10 . Os índices $i$ das posições $s_{i}$ das trajetória curvilíneas foram aproximados para trajetórias retilíneas representadas por $x_{i}$, e correspondem às mesmas extensões percorridas pela frente de onda. As dimensões estimadas de cada uma das secções utilizadas, bem como as grandezas envolvidas no cálculo numérico desenvolvido, são mostradas no Apêndice 2.

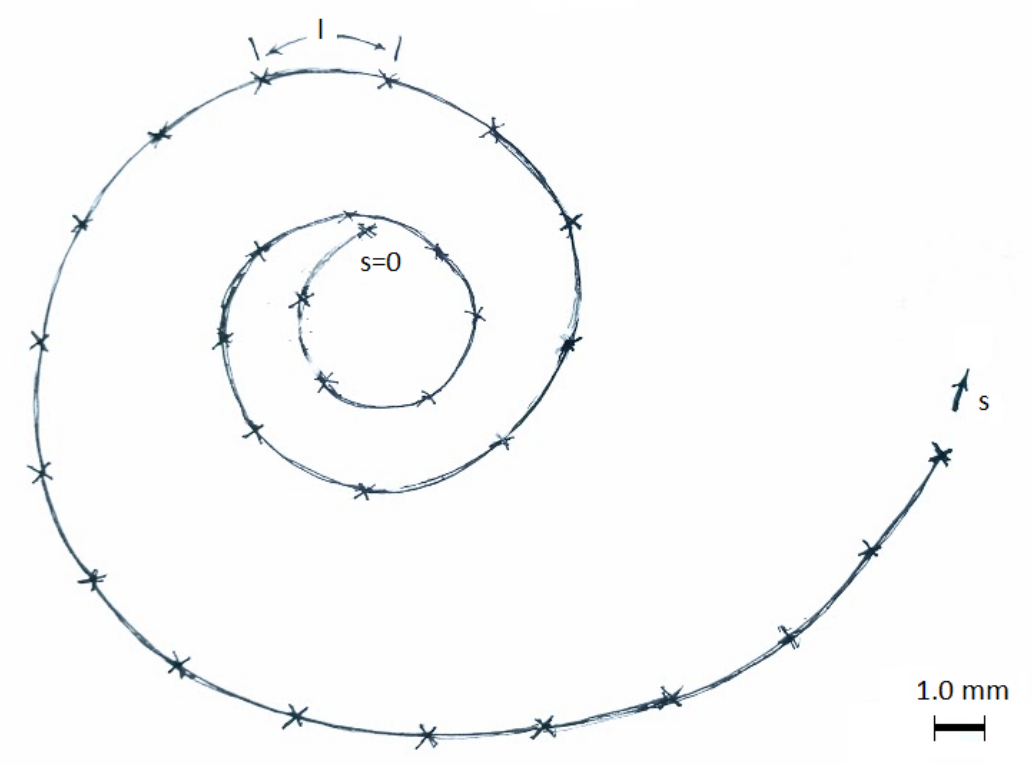

Figura 10: Ilustração esquemática dos segmentos da cóclea utilizados para o cálculo da distribuição da pressão sonora, baseada na fotografia de réplica coclear publicada por Rask-Anderser et al. (RASKANDERSEN et al., 2012). 
A relação $\frac{p}{p_{0}}$ foi calculada numericamente para as frequências $3 k H z, 5 k H z, 10 k H z$ e $20 k H z$, sendo a última o limiar de frequências audíveis em recém-nascidos (BISTAFA, 2011), com base na equação 3.1, e foram adotadas as condições de contorno da extremidade correspondente ao ápice da cóclea, em que assume-se que $A=0$, dados pelas equações 5.1 e 5.2 .

$$
\begin{gathered}
\frac{p(0)}{p_{0}}=1 \\
\frac{d p\left(x=x_{0}\right)}{d x}=0
\end{gathered}
$$

Também foram utilizadas as equações 3.2 e 3.3 para calcular as impedâncias acústicas correspondentes às frequências estudadas em função da posição.

\subsection{Desenvolvimento de Algoritmo Baseado em Modelos de Ban- das Críticas}

Dentre as inúmeras possíveis aplicações dos conceitos acústicos e psicoacústicos estudados, é possível desenvolver algoritmos que filtrem frequências a partir dos modelos de banda crítica supracitados de forma a eliminar ou minimizar a dissonância sensorial.

Em parceria com o músico Micael Antunes da Silva e com o professor Regis Rossi Alves Faria, do Núcleo de Engenharia de Áudio e Codificação Sonora (NEAC), foram desenvolvidos dois trabalhos multidisciplinares com foco na síntese de timbres com base em modelos de dissonância: "An Interactive Tool for the Synthesis of Consonant Timbres Based on Dissonance Models" (uma ferramenta interativa para síntese de timbres consonantes baseados em modelos de dissonância) (SILVA; FARIA; BAYEH, 2017), anexado no Anexo A, e "An Algorithm to Generate Spectra by Decreasing Sensory Dissonance in Equal Tempered Scales" (um algoritmo para gerar espectros através da diminuição da dissonância sensorial em escalas com temperamento por igual) (SILVA; BAYEH; FARIA, 2017), anexado no Anexo B.

Tais trabalhos têm como principal objetivo a aplicação artística dos timbres obtidos, e o presente trabalho abordará apenas os aspectos físicos e psicoacústicos, focando no algoritmo desenvolvido para redução da dissonância sensorial, generalizando o filtro para quaisquer espectros de entrada, e não apenas espectros sintetizados em escalas temperadas arbitrárias, e adicionando o cálculo das bandas críticas de Cambridge. 


\subsubsection{O Algoritmo}

Para reduzir a dissonância sensorial que determinado espectro apresenta, foi desenvolvido um algoritmo que, baseado na discussão sobre bandas críticas apresentada na revisão bibliográfica, exclua parciais de forma a evitar que duas frequências no espectro resultante pertençam à mesma banda crítica.

Desta forma, dado um vetor de entrada com as frequências correspondentes ao espectro a ser filtrado, são utilizadas a equação 4.8 para cálculo das bandas críticas pelo modelo de Cambridge e as equações 4.9 a 4.12 para calcular o número das bandas críticas utilizando-se o modelo de Munique. Tais valores são também armazenados em um vetor para cada um dos modelos.

Em seguida, dois novos vetores de frequências selecionadas para comporem o espectro de saída são utilizados para armazenar o espectro filtrado utilizando-se cada um dos modelos. Seleciona-se arbitrariamente a primeira frequência do vetor de entrada e, a partir de então, cada um dos números de banda crítica correspondentes às frequências seguintes são comparados ao último número selecionado. Quando tal diferença é inferior a 1 Cam e 1 Bark, respectivamente, a frequência correspondente é excluída. Caso contrário, a frequência correspondente é armazenada no vetor de saída correspondente, até se chegar à última frequência do vetor de entrada.

Foi desenvolvido um programa em linguagem $C$, reproduzido no Anexo $\mathrm{C}$, que solicita ao usuário um espectro de entrada, utiliza o algoritmo desenvolvido para filtrar as bandas críticas utilizando ambos os modelos e imprime o espectro filtrado para cada um deles.

\subsubsection{Aplicação - Escalas Temperadas Arbitrárias}

Conforme descrito detalhadamente em (SILVA; BAYEH; FARIA, 2017), o algoritmo de filtro de frequências, utilizando-se o modelo de Munique, foi utilizado a fim de se reduzir a dissonância sensorial em escalas arbitrárias com temperamento por igual, de forma a privilegiar alguns dos parciais, visando-se a síntese de timbre para aplicações artísticas.

É introduzido um número inteiro $n$, representando o número de divisões de um intervalo, convencionando-se $i=2$ como sendo uma oitava, e o vetor $p[]$, indicando os parciais a serem privilegiados. É calculada a razão $r$ da escala, e a partir dela e de uma frequência inicial dada, todas as frequências do espectro são calculadas.

A partir de então, todas as frequências correspondentes aos parciais escolhidos passam pelo filtro utilizando-se o algoritmo supracitado, de forma a eliminar frequências pertencentes à mesma banda crítica.

A figura 11 esquematiza o algoritmo utilizado no trabalho. 


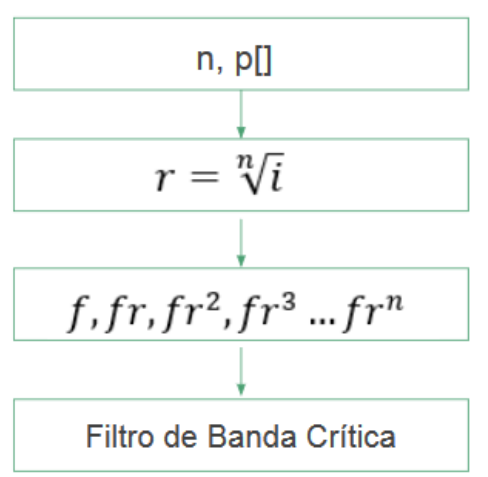

Figura 11: Diagrama esquemático do algoritmo de síntese de timbres reduzindo-se a dissonância sensorial em escalas com temperamento por igual.

O algoritmo foi aplicado em duas situações. Em ambas, a oitava foi dividida igualmente em oito partes e os parciais privilegiados escolhidos correspondem aos passos 2, 4 e 6 da escala. Contudo, no primeiro caso foi determinada frequência inicial de $440 \mathrm{~Hz}$ e no segundo de $1760 \mathrm{~Hz}$. Em ambos os casos também as amplitudes já normalizadas foram arbitrariamente definidas como o inverso do número do parcial correspondente (SILVA; BAYEH; FARIA, 2017).

Foram plotadas as curvas de dissonância correspondentes aos espectros gerados e determinadas por (VASSILAKIS, 2001) a partir das curvas determinadas em (SETHARES, 2005b), indicadas nas equações 4.13 a 4.16. Adaptou-se o código de MatLab desenvolvido também por Sethares (SETHARES, 2005a) de forma a utilizar as equações de (VASSILAKIS, 2001) e de forma a utilizar o eixo horizontal em escala logarítmica. O programa foi executado no software livre GNU Octave, e os códigos adaptados encontram-se anexado no Anexo D.

\subsubsection{Comparação entre os Modelos de Munique e de Cambridge}

Utilizando-se as equações 4.8, que determina a relação entre frequências e número de banda crítica de acordo com o modelo de Cambridge, e as equações 4.9 a 4.12, que determinam tais relações de acordo com o modelo de Munique, foram traçadas curvas comparativas em um gráfico de número de banda crítica (em Cams e Barks, respectivamente) em função da frequência (em $H z)$.

Em seguida, o programa programa foi testado para o espectro harmônico $100 \mathrm{~Hz}$, $200 \mathrm{~Hz}, 300 \mathrm{~Hz}, 400 \mathrm{~Hz}, 500 \mathrm{~Hz}, 600 \mathrm{~Hz}, 700 \mathrm{~Hz}$ e $800 \mathrm{~Hz}$, a fim de se comparar as filtragens baseadas nos dois modelos de bandas críticas.

Foram traçadas as curvas de dissonância para o espectro harmônico original e para ambos os espectros filtrados, para fins comparativos. As amplitudes foram convencionadas como 1. 


\section{Resultados e Discussão}

São apresentados a seguir os resultados e discussões obtidos a partir dos cálculos de pressão sonora e impedância no eixo central da cóclea e do desenvolvimento do algoritmo para filtrar frequências a partir dos modelos de bandas críticas de Munique e Cambridge.

\subsection{Cálculo da pressão sonora ao longo do percurso central da cóclea}

As figuras 12 e 13 apresentam respectivamente o gráfico de pressão sonora relativa e de impedância acústica para as frequências analisadas.

Os resultados dos cálculos realizados mostram que a pressão relativa $p(x)$ a $3 k H z$ é praticamente constante - a variação máxima ao longo de toda a cóclea ocorre a $20 \mathrm{kHz}$ e é inferior a 7\% - indicando baixa perda de energia sonora no órgão coclear. Conforme as frequências aumentam, a pressão sonora diminui, de forma que, a $20 \mathrm{kHz}$, chega a zero na região da base da cóclea, sugerindo compatibilidade com o limiar de audibilidade dado pela literatura. Nas regiões próximas ao pico de audibilidade, a variação de pressão sonora é muito pequena.

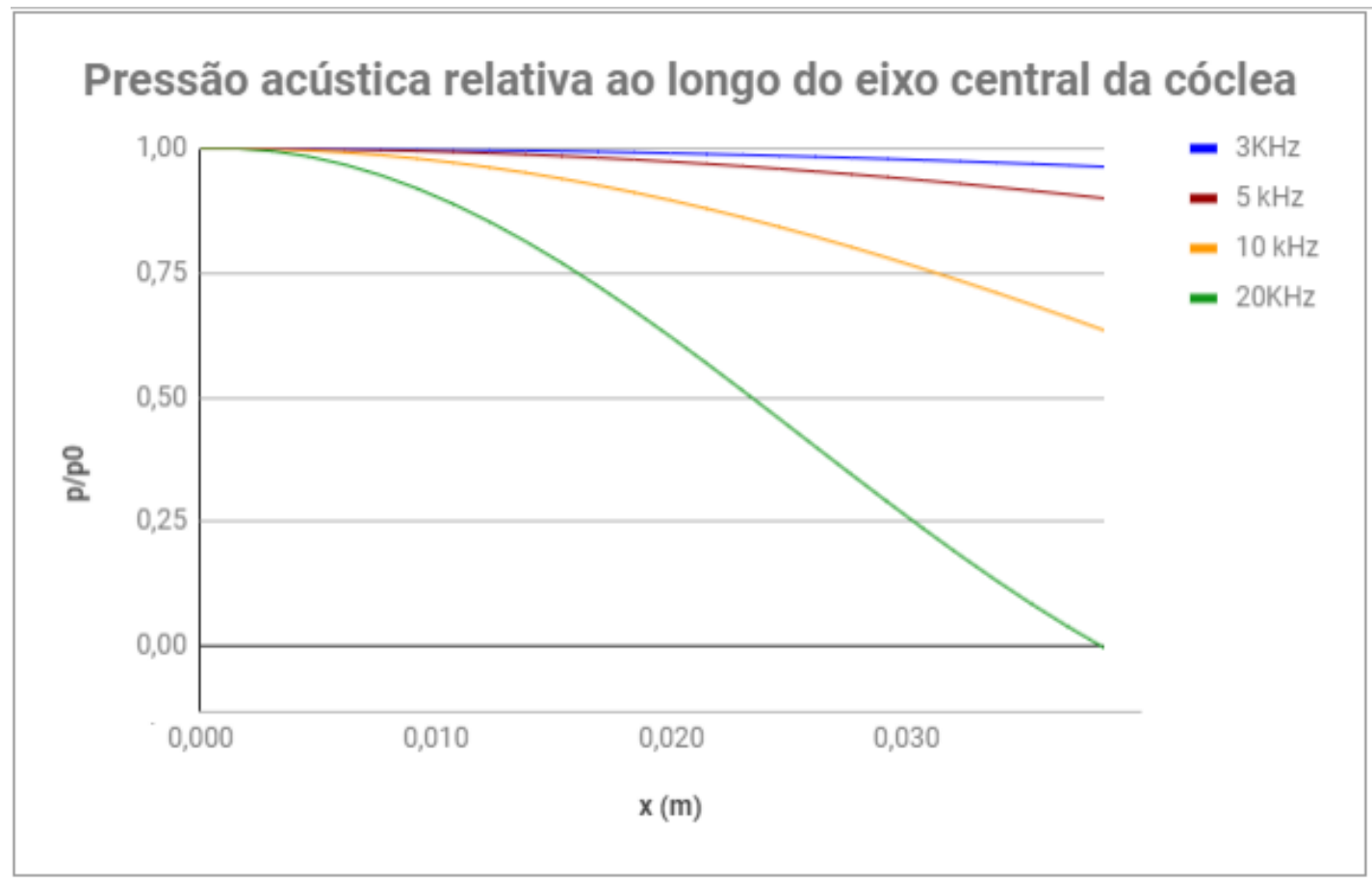

Figura 12: Gráfico de pressão sonora relativa ao longo do eixo central da cóclea para as frequências $3 k H z$, $5 k H z, 10 k H z$ e $20 k H z$. 


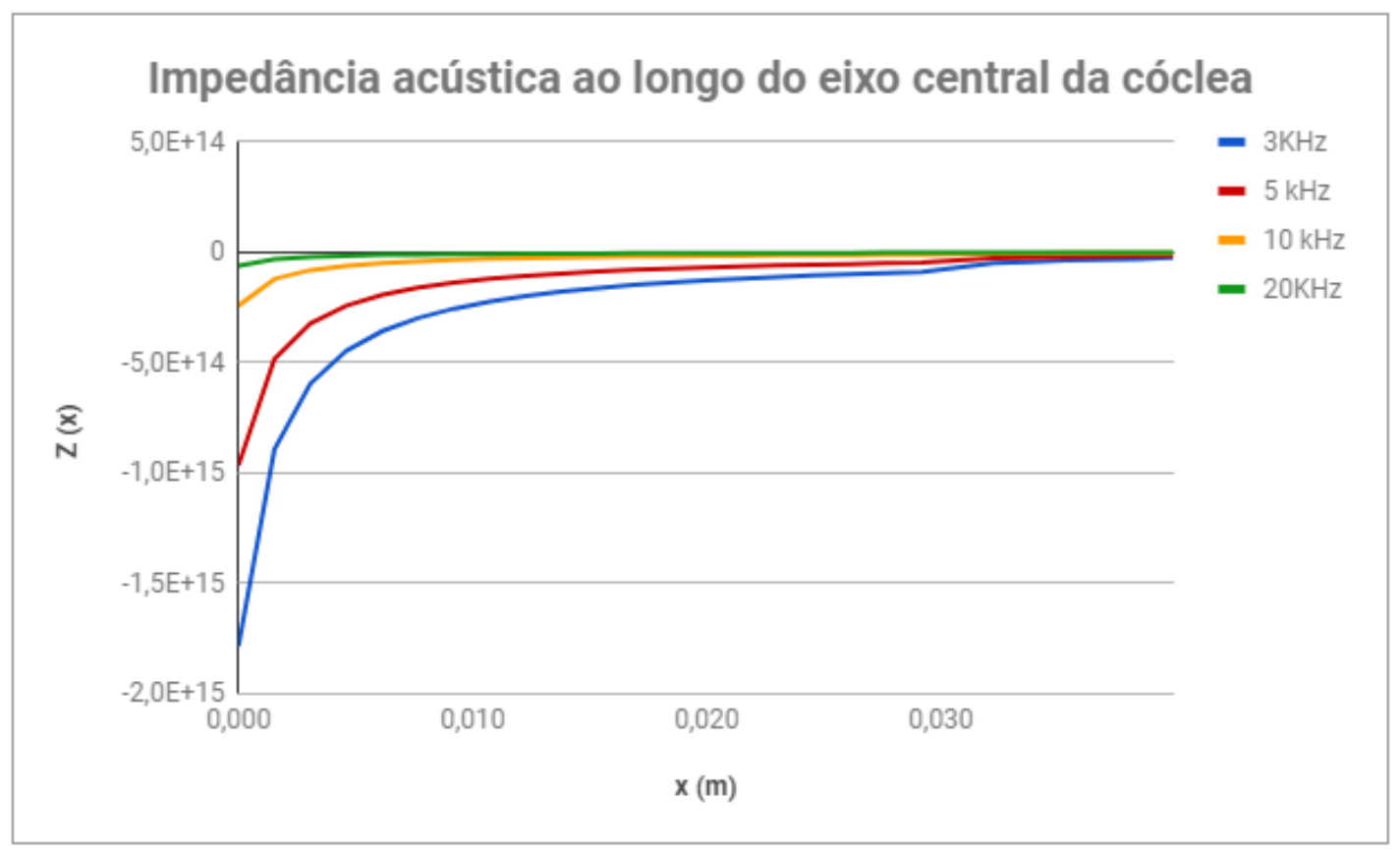

Figura 13: Gráfico de impedância acústica ao longo do eixo central da cóclea para as frequências $3 k H z$, $5 k H z, 10 k H z$ e $20 k H z$.

A impedância acústica ao longo da cóclea é extremamente baixa (da ordem de $\left.-10^{14} \mathrm{kgm}^{-4} \mathrm{~s}^{-1}\right)$. Tais impedâncias são sete ordens de grandeza superiores aos resultados encontrados por Couto (COUTO, 2000), resultado que se deve principalmente à diferença da velocidade de propagação do som entre a água e o ar e às diferenças de densidade da água e do ar. Observa-se também que a impedância é menor para frequências mais baixas.

Ressalta-se que os fenômenos de pressão sonora e impedância acústica na cóclea, aqui representados após uma série de simplificações, apresentam comportamentos lineares, ao contrário de outros fenômenos que ocorrem no interior do órgão coclear. Sugere-se que a eficiência energética da cóclea, tão superior ao restante do aparato auditivo, é de extrema importância para a realização de funções de análise de frequência tão precisas, discutida anteriormente, tendo em vista que ao contrário da orelha externa, a orelha interna recebe o sinal sonoro de forma digital, através de sucessões de pulsos gerados pelo estribo, e dissipações de energia implicariam em perda da qualidade de do sinal e, consequentemente, análise imprecisa das frequências dos estímulos sonoros. 


\subsection{Aplicação do Algoritmo Baseado em Modelos de Bandas Crí- ticas}

\subsubsection{Comparação entre os Modelos de Banda Crítica}

O gráfico exibido na figura 14 indica os números de banda crítica de acordo com os modelos de Cambridge (dado em Cams) e Munique (dado em Barks) em função das frequências correspondentes.

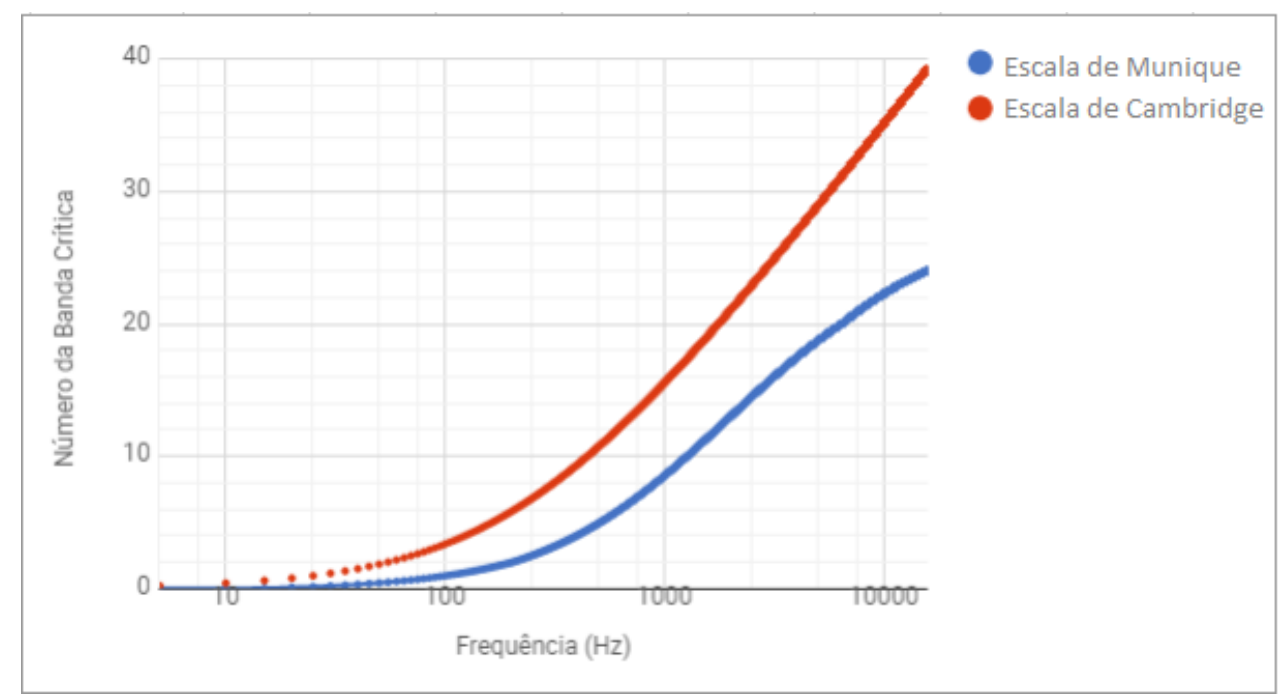

Figura 14: Comparação entre números de banda crítica entre as escalas de Munique (em Barks) e de Cambridge (em Cams).

Observa-se que as bandas críticas do modelo de Cambridge apresentam comportamento mais linear, o que sugere maior equivalência geométrica com a membrana basilar. As bandas críticas do modelo de Munique apresentam maior flutuação na relação entre número das bandas críticas e frequência característica na membrana basilar, além de serem mais largas e, portanto, serem definidas em menor quantidade.

A saída do programa escrito em $C$ para o espectro harmônico $100 \mathrm{~Hz}, 200 \mathrm{~Hz}$, $300 \mathrm{~Hz}, 400 \mathrm{~Hz}, 500 \mathrm{~Hz}, 600 \mathrm{~Hz}, 700 \mathrm{~Hz}$ e $800 \mathrm{~Hz}$ é ilustrado na figura 15.

Observa-se que os espectros impressos são coerentes com seus respectivos filtros e, desta forma, o filtro baseado no modelo de Munique excluiu a frequência $400 \mathrm{~Hz}$ e o filtro baseado no modelo de Cambridge excluiu a frequência $800 \mathrm{~Hz}$.

A figura 16 ilustra as curvas de dissonância sensorial geradas a partir do código em MatLab também anexado no Anexo D, comparando as dissonâncias correspondentes ao espectro inicial e a ambos os espectros filtrados através do algoritmo desenvolvido.

Observa-se que ambos os filtros contribuíram para redução significativa da dissonância sensorial do espectro. Contudo, o filtro de Munique mostrou-se, para este espectro harmônico, mais eficiente. 


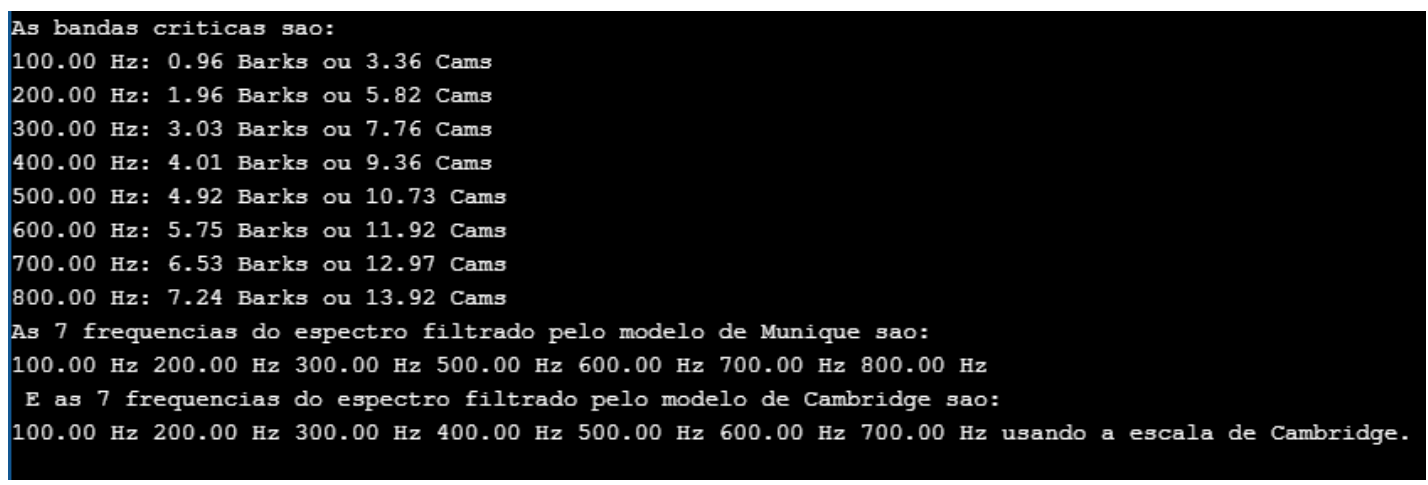

Figura 15: Saída do programa desenvolvido para frequências de entrada $100 \mathrm{~Hz}, 200 \mathrm{~Hz}, 300 \mathrm{~Hz}, 400 \mathrm{~Hz}$, $500 \mathrm{~Hz}, 600 \mathrm{~Hz}, 700 \mathrm{~Hz}$ e $800 \mathrm{~Hz}$.

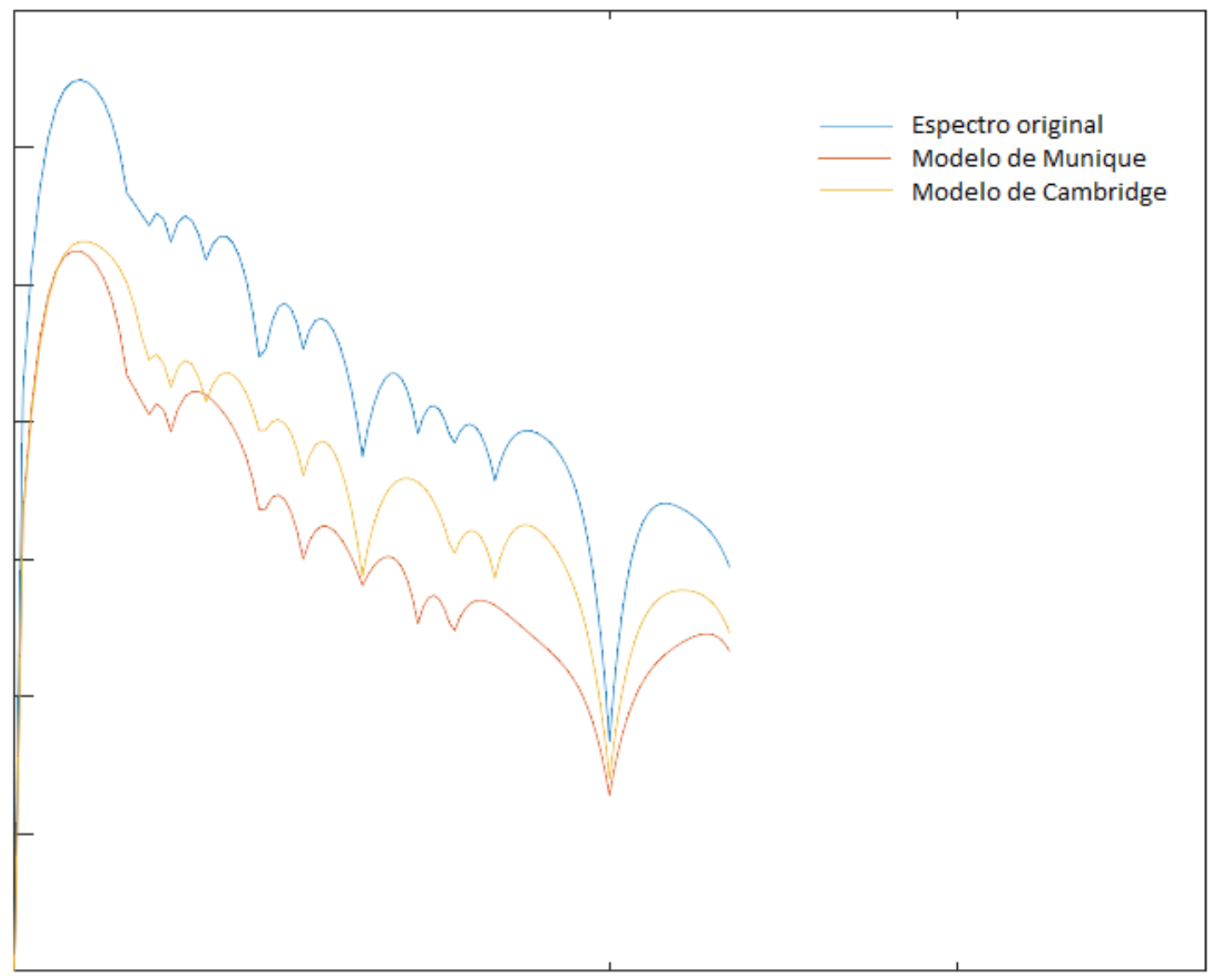

Figura 16: Curvas de dissonância do espectro de frequências original e dos dois espectros filtrados utilizando-se os modelos de Munique e de Cambridge.

Isto provavelmente se deve ao fato de que, neste modelo, as bandas críticas são mais largas e, consequentemente, a filtragem das frequências é mais seletiva, o que se demonstra coerente com o fato de a frequência excluída ser o quarto parcial, enquanto que no filtro correspondente ao modelo de Cambridge, apenas o oitavo parcial foi excluído. 


\subsubsection{Aplicação do Algoritmo a Escalas Temperadas Igualmente Temperadas}

As curvas de dissonância correspondentes às escalas igualmente temperadas geradas a partir do código desenvolvido por Sethares (SETHARES, 2005a) e adaptado de acordo com o modelo de Vassilakis (VASSILAKIS, 2001) são exibidas e discutidas em (SILVA; BAYEH; FARIA, 2017), incorporado no Anexo B.

As curvas de dissonância obtidas para ambas as escalas são exibidas na figura 17.
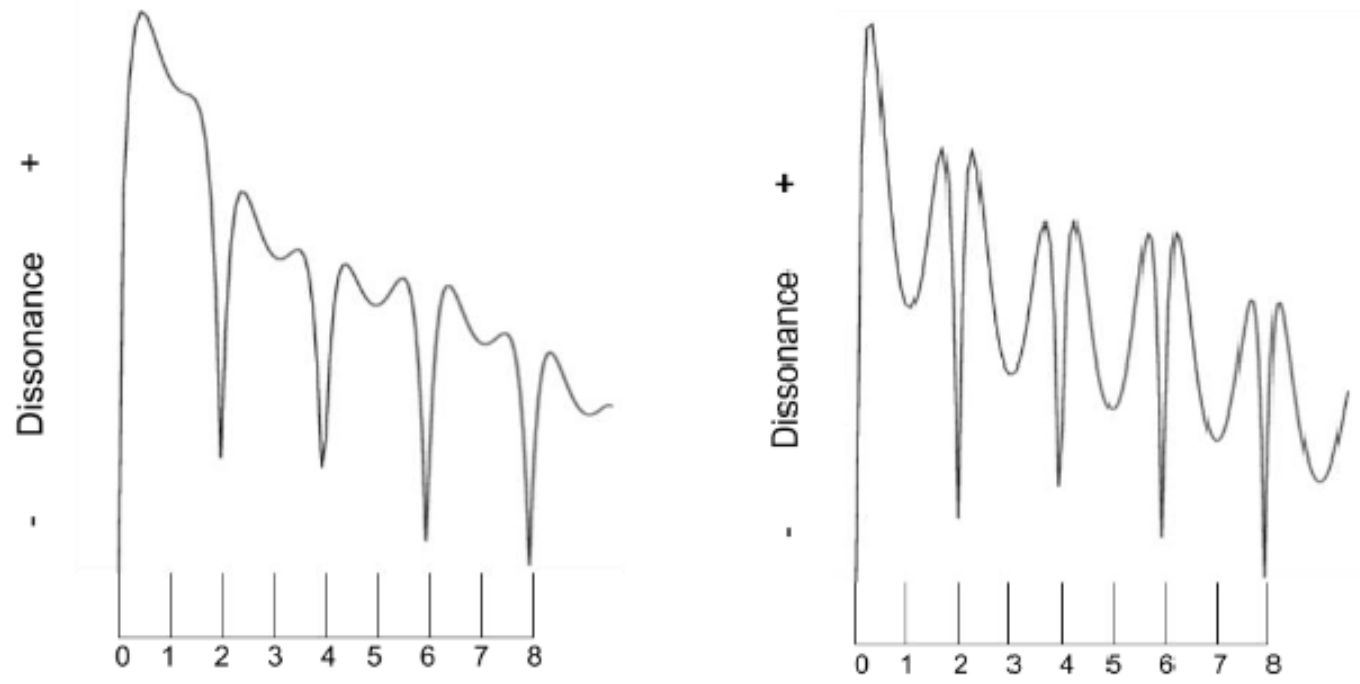

Figura 17: Curvas de dissonância correspondentes às frequências iniciais $440 H z$ (esquerda) e $1760 H z$ (direita). Reproduzido de (SILVA; BAYEH; FARIA, 2017).

Conforme discutido em (SILVA; BAYEH; FARIA, 2017), as curvas demonstram que de fato os mínimos locais coincidem com os parciais que foram escolhidos inicialmente na geração da escala, e que conforme a frequência aumenta, a tais mínimos tendem a diminuir.

Este método demonstrou-se aplicável com sucesso na síntese de timbres visando criações musicais. 



\section{Conclusões}

\subsection{Propriedades Acústicas e Psicoacústicas da Cóclea}

Foi realizada uma revisão bibliográfica dos principais conceitos acústicos e psicoacústicos relacionados à cóclea humana, utilizando-se referências das áreas de medicina, física, psicofísica, musicologia psicologia e biologia.

A partir dos cálculos realizados por Couto (COUTO, 2000), foi possível determinar numericamente a distribuição da pressão sonora e da impedância acústica ao longo do eixo central da cóclea, levando à discussão sobre a alta eficiência energética do aparelho coclear, fundamental na realização da análise de frequências na orelha, que por sua vez é responsável por inúmeros fenômenos perceptivos como o timbre, a consonância e a dissonância.

Foi desenvolvido um algoritmo, aplicado em linguagem $C$, que funcionou para filtrar espectros de frequências de acordo com os modelos de bandas críticas de Cambridge e Munique, e que foi aplicado com sucesso em estudos de dissonância sensorial que utilizaram como base os modelos de Sethares (SETHARES, 2005b) e Vassilakis (VASSILAKIS, 2001).

\subsection{Trabalhos Futuros e Considerações Finais}

Espera-se que os cálculos dos parâmetros físicos, junto aos cálculos realizados anteriormente por Couto, sirvam como base para realização de novos trabalhos na área de física aplicada à orelha humana.

Também propõe-se que a revisão bibliográfica multidisciplinar realizada, os códigos e o algoritmo desenvolvido sejam utilizados tanto por pesquisadores nas áreas de música, psicoacústica e computação musical que desejem desenvolver novos projetos que dialoguem com os conceitos introduzidos neste trabalho quanto por músicos almejando novas aplicações artísticas. 



\section{Referências}

BÉKÉSY, G. V.; WEVER, E. G. Experiments in hearing. [S.l.]: McGraw-Hill New York, 1960. Citado 3 vezes nas páginas 32, 33 e 39.

BENTO, R. F.; MINITI, A.; MARONE, S. Tratado de otologia. [S.l.]: Edusp, 1998. Citado 9 vezes nas páginas 13, 25, 29, 30, 31, 32, 34, 35 e 37.

BISTAFA, S. R. Acústica Aplicada ao Controle do Ruído - $2^{a}$ Edição Revista. [S.l.]: Blucher, 2011. Citado na página 52.

BOER, E. D. A cylindrical cochlea model: The bridge between two and three dimensions. Hearing Research, v. 3, n. 2, p. 109 - 131, 1980. Citado na página 31.

BORSBOOM, M. J.; VIERGEVER, M. A. The stretching nonlinearity of the basilar membrane in a cochlear model. Hearing Research, v. 2, n. 3-4, p. $485-492,1980$. Citado na página 34 .

COUTO, C. M. do. Distribuição da pressão sonora no meato acústico externo. Dissertação (Mestrado) — Universidade de São Paulo, São Paulo, 2000. Citado 8 vezes nas páginas $9,11,30,37,38,51,56$ e 61.

COUTO, C. M. do. O efeito da ressonância das orelhas externa e média na captação das emissões otoacústicas em seres humanos. Tese (Doutorado) - Universidade de São Paulo, São Paulo, 2004. Citado 2 vezes nas páginas 24 e 34.

DANIEL, P. Psychoacoustical roughness. In: Handbook of Signal Processing in Acoustics. New York, NY: Springer New York, 2008. p. 263-274. Citado na página 46.

FAY, J. et al. Three approaches for estimating the elastic modulus of the tympanic membrane. Journal of Biomechanics, v. 38, n. 9, p. 1807 - 1815, 2005. Citado na página 30 .

GOLD, T. Hearing. ii. the physical basis of the action of the cochlea. Proceedings of the Royal Society of London B: Biological Sciences, The Royal Society, v. 135, n. 881, p. 492-498, 1948. Citado na página 34.

HARTMANN, W. M. Signals, sound, and sensation. [S.l.]: Springer Science \& Business Media, 2004. Citado 2 vezes nas páginas 43 e 44.

HELMHOLTZ, H. v. On the sensations of tone, trans. AJ Ellis, Dover, 1954. Citado 6 vezes nas páginas 11, 25, 33, 37, 38 e 46.

HOWARD, D. M.; ANGUS, J. Acoustics and psychoacoustics. [S.l.]: Taylor \& Francis, 2009. Citado na página 43.

HU, S. et al. Research on effecting mechanism of environmental parameters on human ear. Building and Environment, v. 118, p. 289 - 299, 2017. Citado na página 31.

KHANNA, S.; LEONARD, D. Measurement of basilar membrane vibrations and evaluation of the cochlear condition. Hearing Research, v. 23, n. 1, p. $37-53,1986$.

Citado na página 33. 
KINSLER, L. et al. Fundamentals of Acoustics. 3rd. ed. [S.1.]: John Wiley \& Sons, Inc., New York, 1982. Citado 4 vezes nas páginas 37, 40, 43 e 46.

LENT, R. Cem bilhões de neurônios: conceitos fundamentais de neurociência. [S.1.]: Atheneu, 2004. Citado 2 vezes nas páginas 23 e 24.

MAIOLO, A. The Speech Recognition Wiki. 2015. The Speech Recognition Wiki.

Disponível em: <http://www.recognize-speech.com>. Acesso em: 10.10.2017. Citado 2 vezes nas páginas 13 e 46 .

MCADAMS, S. Musical timbre perception. In: DEUTSCH, D. (Ed.). The Psychology of Music. Third edition. [S.1.]: Academic Press, 2013. p. 35-67. ISBN 978-0-12-381460-9. Citado na página 40.

MOORE, B. C. An introduction to the psychology of hearing. [S.l.]: Brill, 2012. Citado 5 vezes nas páginas 13, 31, 32, 33 e 34 .

PELLICCIA, P. et al. Cochlea size variability and implications in clinical practice. Acta Otorhinolaryngologica Italica, v. 34, n. 1, p. 42-49, 2014. Citado na página 31.

PIERCE, J. R. Attaining consonance in arbitrary scales. The Journal of the Acoustical Society of America, Acoustical Society of America, v. 40, n. 1, p. 249-249, 1966. Citado na página 39.

PLOMP, R.; LEVELT, W. J. M. Tonal consonance and critical bandwidth. The journal of the Acoustical Society of America, ASA, v. 38, n. 4, p. 548-560, 1965. Citado 2 vezes nas páginas 39 e 46.

PURIA, S.; ROSOWSKI, J. J. Békésy's contributions to our present understanding of sound conduction to the inner ear. Hearing Research, v. 293, n. 1, p. 21 - 30, 2012. ISSN 0378-5955. "Good Vibrations" A Special Issue to honor the 50 year jubilee for Georg von Békésy's Nobel Prize "The physical mechanisms of stimulation within the cochlea". Citado 3 vezes nas páginas 13, 39 e 40.

RASK-ANDERSEN, H. et al. Human cochlea: Anatomical characteristics and their relevance for cochlear implantation. The Anatomical Record: Advances in Integrative Anatomy and Evolutionary Biology, Wiley Subscription Services, Inc., A Wiley Company, v. 295, n. 11, p. 1791-1811, 2012. Citado 3 vezes nas páginas 13, 33 e 51.

ROBLES, L.; RUGGERO, M. A. Mechanics of the mammalian cochlea. Physiological reviews, Am Physiological Soc, v. 81, n. 3, p. 1305-1352, 2001. Citado na página 33.

ROCHEFOUCAULD, O. de L. et al. Simultaneous measurements of ossicular velocity and intracochlear pressure leading to the cochlear input impedance in gerbil. Journal of the Association for Research in Otolaryngology, v. 9, n. 2, p. 161-177, Jun 2008. Citado na página 39 .

ROEDERER, J. G. The physics and psychophysics of music: an introduction. [S.1.]: Springer Verlag, 1995. Citado na página 25.

RUGGERO, M. A. Responses to sound of the basilar membrane of the mammalian cochlea. Current opinion in neurobiology, Elsevier, v. 2, n. 4, p. 449-456, 1992. Citado na página 24 . 
RUGGERO, M. A.; RICH, N. C. Application of a commercially-manufactured doppler-shift laser velocimeter to the measurement of basilar-membrane vibration. Hearing Research, v. 51, n. 2, p. 215 - 230, 1991. Citado na página 24.

RUGGERO, M. A.; RICH, N. C. Application of a commercially-manufactured doppler-shift laser velocimeter to the measurement of basilar-membrane vibration. Hearing Research, v. 51, n. 2, p. 215 - 230, 1991. Citado na página 33.

SETHARES, W. Some useful computer programs. 2005. The Speech Recognition Wiki. Disponível em: <http://sethares.engr.wisc.edu/comprog.html>. Acesso em: 18.9.2017. Citado 3 vezes nas páginas 54, 59 e 97.

SETHARES, W. A. Tuning, timbre, spectrum, scale. [S.1.]: Springer Science \& Business Media, 2005. Citado 3 vezes nas páginas 47, 54 e 61.

SILVA, L. C. N. da. Fascínio e Repulsa por Sereias de Metal-Determinantes acústicas, psíquicas e biográfico-culturais - ou, necessidade e contingência - na musicologia de Hermann von Helmholtz. Dissertação (Mestrado) - Universidade de São Paulo, São Paulo, 2017. Citado na página 38.

SILVA, M. A. da; BAYEH, R.; FARIA, R. R. A. An algorithm to generate spectra by decreasing sensory dissonance in equal tempered scales. In: Memorias del III Congreso Internacional de Ciencia y Tecnología Musical (CICTeM) - "La música electroacústica como impulsora del conocimiento". [S.1.: s.n.], 2017. p. 29-33. Citado 7 vezes nas páginas $14,47,52,53,54,59$ e 87.

SILVA, M. A. da; FARIA, R. R. A.; BAYEH, R. An interactive tool for the synthesis of consonant timbres based on dissonance models. In: 13th International Symposium on Computer Music Multidisciplinary Research (CMMR). [S.l.: s.n.], 2017. p. 450-458. Citado 3 vezes nas páginas 47, 52 e 77.

SKRODZKA, E. B. Mechanical passive and active models of the human basilar membrane. Applied Acoustics, v. 66, n. 12, p. 1321 - 1338, 2005. Citado na página 33.

SONG, X. et al. Complex pitch perception mechanisms are shared by humans and a new world monkey. Proceedings of the National Academy of Sciences, v. 113, n. 3, p. 781-786, 2016. Citado na página 24.

STINSON, M. R. The spatial distribution of sound pressure within scaled replicas of the human ear canal. The Journal of the Acoustical Society of America, v. 78, n. 5, p. 1596-1602, 1985. Citado na página 37.

STINSON, M. R. Revision of estimates of acoustic energy reflectance at the human eardrum. The Journal of the Acoustical Society of America, v. 88, n. 4, p. 1773-1778, 1990. Citado na página 31.

THORET, E.; DEPALLE, P.; MCADAMS, S. Perceptually salient regions of the modulation power spectrum for musical instrument identification. v. 8, p. 587, 032017. Citado na página 41.

TONNDORF, J.; KHANNA, S. M. Tympanic-membrane vibrations in human cadaver ears studied by time averaged holography. The Journal of the Acoustical Society of America, v. 52, n. 4B, p. 1221-1223, 1972. Citado 3 vezes nas páginas 13, 39 e 40. 
TRAUNMÜLLER, H. Analytical expressions for the tonotopic sensory scale. The Journal of the Acoustical Society of America, ASA, v. 88, n. 1, p. 97-100, 1990. Citado na página 44 .

VASSILAKIS, P. N. Perceptual and physical properties of amplitude fluctuation and their musical significance. Tese (Doutorado) - University of California - Los Angeles, 2001. Citado 5 vezes nas páginas 47, 54, 59, 61 e 97.

VOSS, S. et al. Non-ossicular signal transmission in human middle ears: Experimental assessment of the "acoustic route" with perforated tympanic membranes. Acoustical Society of America Journal, v. 122, p. 2135, 2007. Citado na página 30.

VOSS, S. E.; ROSOWSKI, J. J.; PEAKE, W. T. Is the pressure difference between the oval and round windows the effective acoustic stimulus for the cochlea? The Journal of the Acoustical Society of America, v. 100, n. 3, p. 1602-1616, 1996. Citado na página 33.

WIKIMEDIA. Ear Anatomy. 2013. Ear Anatomy. Disponível em: <http://commons.wikimedia.org/wiki/File:Ear-anatomy.png >. Acesso em: 15.9.2017. Citado 2 vezes nas páginas 13 e 29.

WIKIMEDIA. Bark Scale. 2016. Bark Scale. Disponível em: <http://commons.wikimedia.org/wiki/File:Bark_scale.png>. Acesso em: 15.1.2018. Citado 2 vezes nas páginas 13 e 45 .

ZWICKER, E. Subdivision of the audible frequency range into critical bands (frequenzgruppen). The Journal of the Acoustical Society of America, v. 33, n. 2, p. 248-248, 1961. Citado 3 vezes nas páginas 15, 44 e 69.

ZWICKER, E.; FASTL, H. Psychoacoustics: Facts and models. [S.1.]: Springer Science \& Business Media, 2013. Citado na página 35.

ZWICKER, E.; FLOTTORP, G.; STEVENS, S. S. Critical band width in loudness summation. The Journal of the Acoustical Society of America, ASA, v. 29, n. 5, p. 548-557, 1957. Citado na página 43. 
Apêndices 



\section{APÊNDICE A - Escala de Bark - Zwicker}

\begin{tabular}{llcc}
$\begin{array}{l}\text { Número } \\
\text { (Bark) }\end{array}$ & $\begin{array}{l}\text { Frequência } \\
\text { Central }(\mathrm{Hz})\end{array}$ & $\begin{array}{c}\text { Frequência de } \\
\text { Corte }(\mathrm{Hz})\end{array}$ & $\begin{array}{c}\text { Largura da } \\
\text { Banda }(\mathrm{Hz})\end{array}$ \\
\hline 1 & 60 & 20 & \\
2 & 150 & 100 & 80 \\
3 & 250 & 200 & 100 \\
4 & 350 & 300 & 100 \\
5 & 450 & 400 & 100 \\
6 & 570 & 510 & 110 \\
7 & 700 & 630 & 120 \\
8 & 840 & 770 & 140 \\
9 & 1000 & 920 & 150 \\
10 & 1170 & 1080 & 160 \\
11 & 1370 & 1270 & 190 \\
12 & 1600 & 1480 & 210 \\
13 & 1850 & 1720 & 240 \\
14 & 2150 & 2000 & 280 \\
15 & 2500 & 2320 & 320 \\
16 & 2900 & 2700 & 380 \\
17 & 3400 & 3150 & 450 \\
18 & 4000 & 3700 & 550 \\
19 & 4800 & 4400 & 700 \\
20 & 5800 & 5300 & 900 \\
21 & 7000 & 6400 & 1100 \\
22 & 8500 & 7700 & 1300 \\
23 & 10500 & 9500 & 1800 \\
24 & 13500 & 12000 & 2500 \\
& & 15500 & 3500
\end{tabular}

Tabela 1: Tabela de bandas críticas em escala Bark, traduzido e adaptado de Zwicker (ZWICKER, 1961) 



\section{APÊNDICE B - Cálculo da Distribuição da Pressão Sonora}

As tabelas abaixo indicam os valores estimados de área para cada secção da cóclea e os respectivos valores calculados de pressão sonora relativa e impedância acústica para as quatro frequências analisadas.

\begin{tabular}{ccc}
$\mathrm{i}$ & $x_{i}(\mathrm{~mm})$ & $\sigma\left(\mathrm{mm}^{2}\right)$ \\
\hline 1 & 0,000 & 0,870 \\
2 & 1,536 & 0,870 \\
3 & 3,072 & 0,870 \\
4 & 4,608 & 0,870 \\
5 & 6,144 & 0,870 \\
6 & 7,680 & 0,870 \\
7 & 9,216 & 0,870 \\
8 & 10,752 & 0,870 \\
9 & 12,288 & 0,870 \\
10 & 13,824 & 0,870 \\
11 & 15,360 & 0,870 \\
12 & 16,896 & 0,870 \\
13 & 18,432 & 0,870 \\
14 & 19,968 & 0,870 \\
15 & 21,504 & 0,870 \\
16 & 23,040 & 0,870 \\
17 & 24,576 & 0,870 \\
18 & 26,112 & 0,870 \\
19 & 27,648 & 0,870 \\
20 & 29,184 & 0,870 \\
21 & 30,720 & 1,050 \\
22 & 32,256 & 1,410 \\
23 & 33,792 & 1,530 \\
24 & 35,328 & 1,710 \\
25 & 36,864 & 1,830 \\
26 & 38,400 & 1,890 \\
27 & 39,936 & 2,440 \\
& &
\end{tabular}

Tabela 2: Posições na cóclea e áreas das secções transversais estimadas para realização do cálculo de pressão sonora relativa e impedância acústica. 


\begin{tabular}{ccccc}
$\mathrm{i}$ & $p_{i}(3 k H z)$ & $Z_{i}(3 k H z)$ & $p_{i}(5 k H z)$ & $Z_{i}(5 k H z)$ \\
\hline 1 & 1,000 & $-1,79 \mathrm{E}+15$ & 1,000 & $-9,66 \mathrm{E}+14$ \\
2 & 1,000 & $-8,92 \mathrm{E}+14$ & 1,000 & $-4,83 \mathrm{E}+14$ \\
3 & 1,000 & $-5,95 \mathrm{E}+14$ & 1,000 & $-3,22 \mathrm{E}+14$ \\
4 & 1,000 & $-4,46 \mathrm{E}+14$ & 0,999 & $-2,41 \mathrm{E}+14$ \\
5 & 0,999 & $-3,57 \mathrm{E}+14$ & 0,998 & $-1,93 \mathrm{E}+14$ \\
6 & 0,999 & $-2,97 \mathrm{E}+14$ & 0,997 & $-1,61 \mathrm{E}+14$ \\
7 & 0,998 & $-2,55 \mathrm{E}+14$ & 0,995 & $-1,38 \mathrm{E}+14$ \\
8 & 0,997 & $-2,23 \mathrm{E}+14$ & 0,993 & $-1,20 \mathrm{E}+14$ \\
9 & 0,997 & $-1,98 \mathrm{E}+14$ & 0,990 & $-1,07 \mathrm{E}+14$ \\
10 & 0,996 & $-1,78 \mathrm{E}+14$ & 0,988 & $-9,61 \mathrm{E}+13$ \\
11 & 0,994 & $-1,62 \mathrm{E}+14$ & 0,985 & $-8,72 \mathrm{E}+13$ \\
12 & 0,993 & $-1,48 \mathrm{E}+14$ & 0,981 & $-7,98 \mathrm{E}+13$ \\
13 & 0,992 & $-1,37 \mathrm{E}+14$ & 0,977 & $-7,36 \mathrm{E}+13$ \\
14 & 0,990 & $-1,27 \mathrm{E}+14$ & 0,973 & $-6,82 \mathrm{E}+13$ \\
15 & 0,989 & $-1,18 \mathrm{E}+14$ & 0,969 & $-6,35 \mathrm{E}+13$ \\
16 & 0,987 & $-1,11 \mathrm{E}+14$ & 0,964 & $-5,94 \mathrm{E}+13$ \\
17 & 0,985 & $-1,04 \mathrm{E}+14$ & 0,959 & $-5,58 \mathrm{E}+13$ \\
18 & 0,983 & $-9,85 \mathrm{E}+13$ & 0,954 & $-5,26 \mathrm{E}+13$ \\
19 & 0,981 & $-9,32 \mathrm{E}+13$ & 0,948 & $-4,97 \mathrm{E}+13$ \\
20 & 0,979 & $-8,85 \mathrm{E}+13$ & 0,942 & $-4,71 \mathrm{E}+13$ \\
21 & 0,977 & $-6,97 \mathrm{E}+13$ & 0,936 & $-3,71 \mathrm{E}+13$ \\
22 & 0,974 & $-4,95 \mathrm{E}+13$ & 0,929 & $-2,63 \mathrm{E}+13$ \\
23 & 0,972 & $-4,36 \mathrm{E}+13$ & 0,922 & $-2,31 \mathrm{E}+13$ \\
24 & 0,969 & $-3,74 \mathrm{E}+13$ & 0,915 & $-1,97 \mathrm{E}+13$ \\
25 & 0,966 & $-3,35 \mathrm{E}+13$ & 0,907 & $-1,76 \mathrm{E}+13$ \\
26 & 0,963 & $-3,11 \mathrm{E}+13$ & 0,900 & $-1,64 \mathrm{E}+13$ \\
27 & 0,960 & $-2,32 \mathrm{E}+13$ & 0,892 & $-1,22 \mathrm{E}+13$
\end{tabular}

Tabela 3: Valores calculados de pressão sonora relativa e impedância acústica para as frequências $3 k H z$ e $5 k H z$. 


\begin{tabular}{ccccc}
$\mathrm{i}$ & $p_{i}(10 k H z)$ & $Z_{i}(10 k H z)$ & $p_{i}(20 k H z)$ & $Z_{i}(20 k H z)$ \\
\hline 1 & 1,000 & $-2,42 \mathrm{E}+14$ & 1,000 & $-6,05 \mathrm{E}+13$ \\
2 & 1,000 & $-1,21 \mathrm{E}+14$ & 1,000 & $-3,02 \mathrm{E}+13$ \\
3 & 0,999 & $-8,04 \mathrm{E}+13$ & 0,994 & $-2,01 \mathrm{E}+13$ \\
4 & 0,996 & $-6,03 \mathrm{E}+13$ & 0,984 & $-1,50 \mathrm{E}+13$ \\
5 & 0,992 & $-4,81 \mathrm{E}+13$ & 0,967 & $-1,19 \mathrm{E}+13$ \\
6 & 0,986 & $-4,00 \mathrm{E}+13$ & 0,946 & $-9,82 \mathrm{E}+12$ \\
7 & 0,979 & $-3,42 \mathrm{E}+13$ & 0,919 & $-8,31 \mathrm{E}+12$ \\
8 & 0,971 & $-2,98 \mathrm{E}+13$ & 0,888 & $-7,16 \mathrm{E}+12$ \\
9 & 0,962 & $-2,64 \mathrm{E}+13$ & 0,852 & $-6,25 \mathrm{E}+12$ \\
10 & 0,951 & $-2,36 \mathrm{E}+13$ & 0,813 & $-5,50 \mathrm{E}+12$ \\
11 & 0,939 & $-2,14 \mathrm{E}+13$ & 0,769 & $-4,88 \mathrm{E}+12$ \\
12 & 0,926 & $-1,95 \mathrm{E}+13$ & 0,723 & $-4,34 \mathrm{E}+12$ \\
13 & 0,911 & $-1,79 \mathrm{E}+13$ & 0,674 & $-3,87 \mathrm{E}+12$ \\
14 & 0,896 & $-1,65 \mathrm{E}+13$ & 0,622 & $-3,45 \mathrm{E}+12$ \\
15 & 0,879 & $-1,52 \mathrm{E}+13$ & 0,568 & $-3,07 \mathrm{E}+12$ \\
16 & 0,861 & $-1,42 \mathrm{E}+13$ & 0,513 & $-2,72 \mathrm{E}+12$ \\
17 & 0,842 & $-1,32 \mathrm{E}+13$ & 0,458 & $-2,39 \mathrm{E}+12$ \\
18 & 0,823 & $-1,23 \mathrm{E}+13$ & 0,401 & $-2,08 \mathrm{E}+12$ \\
19 & 0,802 & $-1,15 \mathrm{E}+13$ & 0,345 & $-1,78 \mathrm{E}+12$ \\
20 & 0,780 & $-1,08 \mathrm{E}+13$ & 0,290 & $-1,49 \mathrm{E}+12$ \\
21 & 0,758 & $-8,44 \mathrm{E}+12$ & 0,236 & $-1,00 \mathrm{E}+12$ \\
22 & 0,734 & $-5,91 \mathrm{E}+12$ & 0,183 & $-5,66 \mathrm{E}+11$ \\
23 & 0,710 & $-5,13 \mathrm{E}+12$ & 0,133 & $-3,53 \mathrm{E}+11$ \\
24 & 0,686 & $-4,33 \mathrm{E}+12$ & 0,085 & $-1,57 \mathrm{E}+11$ \\
25 & 0,660 & $-3,81 \mathrm{E}+12$ & 0,039 & $1,30 \mathrm{E}+10$ \\
26 & 0,635 & $-3,48 \mathrm{E}+12$ & $-0,003$ & $1,83 \mathrm{E}+11$ \\
27 & 0,608 & $-2,54 \mathrm{E}+12$ & $-0,042$ & $2,92 \mathrm{E}+11$
\end{tabular}

Tabela 4: Valores calculados de pressão sonora relativa e impedância acústica para as frequências $10 \mathrm{kHz}$ e $20 k H z$. 

Anexos 



\section{ANEXO A - Artigo Apresentado - CMMR 2017}

A seguir, o artigo "An Interactive Tool for the Synthesis of Consonant Timbres Based on Dissonance Models" (uma ferramenta interativa para síntese de timbres consonantes baseados em modelos de dissonância) (SILVA; FARIA; BAYEH, 2017), apresentado na forma de poster no 13th International Symposium on Computer Music Multidisciplinary Research (CMMR), em setembro de 2017 em Matosinhos, Portugal. 


\title{
An Interactive Tool for the Synthesis of Consonant Timbres Based on Dissonance Models
}

\author{
Micael Antunes da Silva ${ }^{1}$, Regis Rossi Alves Faria ${ }^{1,2}$ and Rebeca Bayeh ${ }^{3}$ \\ 1 Research Centre on Sonology, School of Arts and Communications, University of São \\ Paulo, São Paulo, Brazil \\ 2 Laboratory of Musical Acoustics and Technology, Faculty of Philosophy, Sciences and \\ Letters of Ribeirão Preto, University of São Paulo, Ribeirão Preto, Brazil \\ 3 Department of General Physics, Institute of Physics, University of São Paulo, São Paulo, \\ Brazil \\ micael.antunes@usp.br, regis@usp.br,rebeca.bayeh@usp.br
}

\begin{abstract}
This article describes the implementation of an interactive software patch for Pure Data $(\mathrm{Pd})$ that aims to generate consonant timbres by selecting and manipulating spectra partials using dissonance models to improve the consonance between intervals. First, we describe the technique used to create spectra based on Sethares' and Vassilakis' models of sensory dissonance. Then, we propose a method for reducing dissonance by designing an appropriate spectra for a given target equal tempered scale. A patch to generate the timbre sounds is presented, which can be played using a MIDI keyboard. At last, we show an example of a timbre spectrum generated by our patch and validate the method efficacy by inspecting its corresponding dissonance curve.
\end{abstract}

Keywords: Consonant timbres; Dissonance models; Psychoacoustics; Equal tempered scales;

\section{Introduction}

Dissonance is a multidimensional attribute of the sound that can be approached through many ways, considering cultural aspects, the musical practice, and the physical properties of the sound. Tenney [4] divides those approaches in five different categories: melodic, polyphonic, functional, contrapunctual and psychoacoustics. In the present research, we do not consider cultural and aesthetic factors, but focus on the concept of psychoacoustic dissonance using a psychophysics approach. Our main motivation is the search for methods to enhance the sense of consonance in both chords and melodic sequences of notes for equal tempered scales, especially for those using a number of divisions rather than the traditional 12-tone chromatic scale.

Helmholtz introduced the concept of roughness in his theory of beats [5], that states that the perception of dissonance is related to the presence of beats between partials. According to this principle, the perception of the highest dissonance between two pure tones occurs when the difference of frequencies between the tones is between $30 \mathrm{~Hz}$ and $40 \mathrm{~Hz}$, at any register.

Plomp and Levelt in 1965 [6] reviewed the theory of beats based on the concept of critical bandwidth. Based on a subjective experiment that presented pairs of sinusoidal 
sounds to volunteers without musical training, they concluded that the roughness sensation happens only in intervals that are situated in the same critical bandwidth, a conception that persists until today. The highest roughness sensation happens at around a quarter of the critical bandwidth, that exhibit different extensions according to the register, being larger at low frequencies and smaller at high frequencies. We can see in fig. 1 a dissonance curve for a 12-step equal tempered scale, resulting from Plomp and Levelt's experiment.

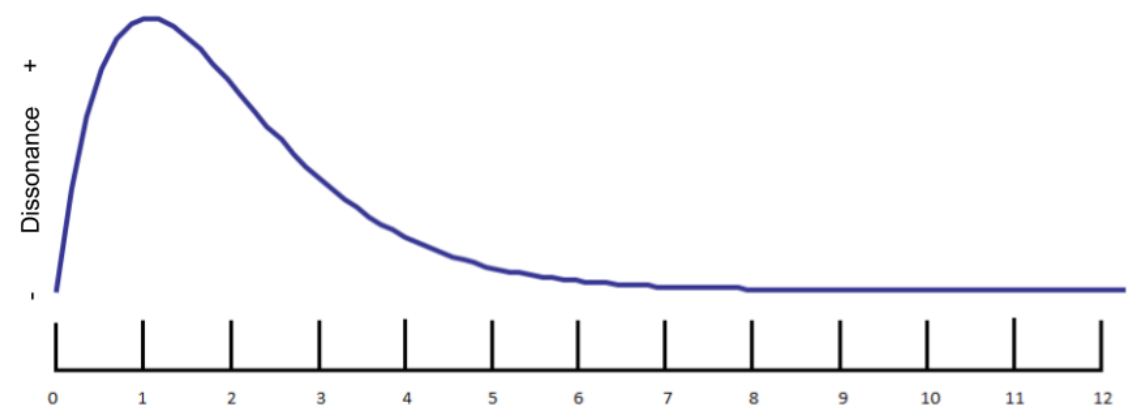

Fig. 1. Dissonance curve obtained by Plomp and Levelt [6]. The $\mathrm{x}$ axis represents the pitch span over an octave, indicating the 12 steps of 12 -tet scale.

Following our developments pursuing a method for reducing the dissonance between steps of an arbitrary n-step equal tempered musical scale [9], the next sections will lead to the implementation of an interactive patch for Pure Data $(\mathrm{Pd})$ that can synthesize an artificial spectrum, related to a given desired equal tempered scale, that shall exhibit an optimized consonance for a specified number of interval steps.

\section{The Dissonance Model}

Sethares [2] approximates the dissonance curve of fig.1 with the function on eq. 1.

$$
d(x)=e^{-b_{1} x}-e^{-b_{2} x}
$$

where $\mathrm{x}$ represents the absolute value of the difference of frequencies between two pure tones and the exponents $b_{1}$ and $b_{2}$ represent the rates of rise and fall of the curve.

Based on this approximation, Sethares introduces the function of dissonance $d$ (eq. 2 ), where $f_{1}<f_{2}$, and $s$ is given by eq. 3, where $x_{m}$ is the point of maximum dissonance and the values of $b_{1}, b_{2}, s_{1}$ and $s_{2}$ are determined from the minimization of quadratic errors by the gradient method [2] of the dissonance curve of figure 1 and are respectively $b_{1}=3.5, b_{2}=5.75, s_{1}=0.021$ and $s_{2}=19$.

Sethares' model takes into consideration the loudness to estimate the dissonance between partials with different amplitudes. He introduces then the variable $l_{12}$ defined by (4). 


$$
\begin{gathered}
d\left(f_{1}, f_{2}, l_{1}, l_{2}\right)=l_{12}\left[e^{-b_{1} s\left(f_{2}-f_{1}\right)}-e^{-b_{2} s\left(f_{2}-f_{1}\right)}\right] \\
s=\frac{x_{m}}{s_{1} f_{1}+s_{2}} \\
l_{12}=\min \left(l_{1}, l_{2}\right)
\end{gathered}
$$

The dissonance level for a complex sound will be given by the combination of the dissonance levels of each pair of partials. Vassilakis [8] uses the results of subjective tests by Terhardt [7] to substantiate his revision of Sethares' model. This revision affects only the estimation of roughness with pure tones of different amplitudes. Vassilakis' revision was motivated by the fact that Sethares' model overestimates the SPL and underestimates the degree of amplitude fluctuation of the partials. Such revision can be expressed in the following equation:

$$
R\left(f_{1}, f_{2}, l_{1}, l_{2}\right)=\left(l_{1} * l_{2}\right)^{0.1} * 0.5\left(\frac{2 l_{2}}{l_{1+l}}\right){ }^{3.11}\left[e^{-b_{1} 2\left(f_{2}-f_{1}\right)}-e^{-b_{2} s\left(f_{2}-f_{1}\right)}\right]
$$

where $b_{1}=3.5, b_{2}=5.75, s=\frac{x m}{s_{1} f_{1}+s_{2}}, x_{m}=0.24, s_{1}=0.0207$ and $s_{2}=18.96$.

\section{The Method for Building Consonant Timbre Spectra}

Based on the experiences of Sethares [2] and Pierce [1] in the construction of spectrum related to scales, and following the strategies presented in [9], we propose a 3 -stage method for the construction of spectra related to an equal tempered scale ${ }^{1}$.

The construction of a spectrum related to a scale aims to minimize the sensorial dissonance by reducing roughness sensation between the scale notes through manipulation of the spectrum partials. This procedure should produce an adequate set of partial amplitudes and ratios to the fundamental frequency to be used as a stationary spectrum for the sustain segment of each note of the scale played. Its fundamental frequency and an adequate balance of chosen partials' amplitudes determine the pitch sensation for each note.

The three stages, illustrated in Figure 2, are to set: 1- the ratio of the chosen scale; 2 - the chosen scale steps that will be privileged in terms of improved consonance; 3 the distribution of partials over the critical bands.

\footnotetext{
${ }^{1}$ By equal tempered scale we mean any scale that divides a given interval - e.g an octave - into $n$ equal parts.
} 


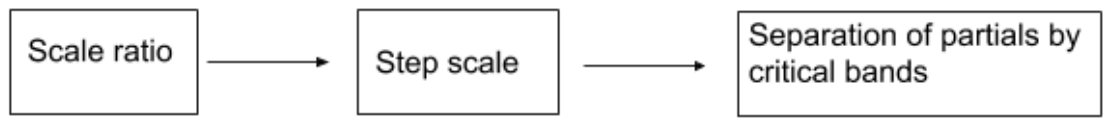

Fig. 2. Steps for the construction of an improved consonant spectrum for a given scale

These tasks aims to minimize the sensorial dissonance in the spectrum of a given $n$ tet equal tempered scale and to enable the choice of consonant dyads in the scale.

\section{The Pure Data Patch Structure}

The next sub-sections present a Pd patch that calculates the partials frequencies to be used in the synthesis of each note for a given n-tet scale, and implements a simple synthesizer to generate the sounds. Its user interface collects some design rules and choices, including a method to define partials amplitudes.

\subsection{The front-end of patch interface}

Figure 3 shows the front-end interface of the patch. In the field N-tet of spectra we determine the equal tempered scale that will generate the spectrum. In the field Scale Steps we choose the scale steps candidates to the lowest dissonance levels, from 3 to 5 steps. In the field $N$-tet key we can determine which equal tempered scale will execute the spectrum. In the box Amplitudes, we can choose between 4 options of equalization for the partials' amplitudes. At the bottom of the screen, one can see the values of the synthesized spectrum partials and their amplitudes, and the print button will send these values to Pure Data terminal.

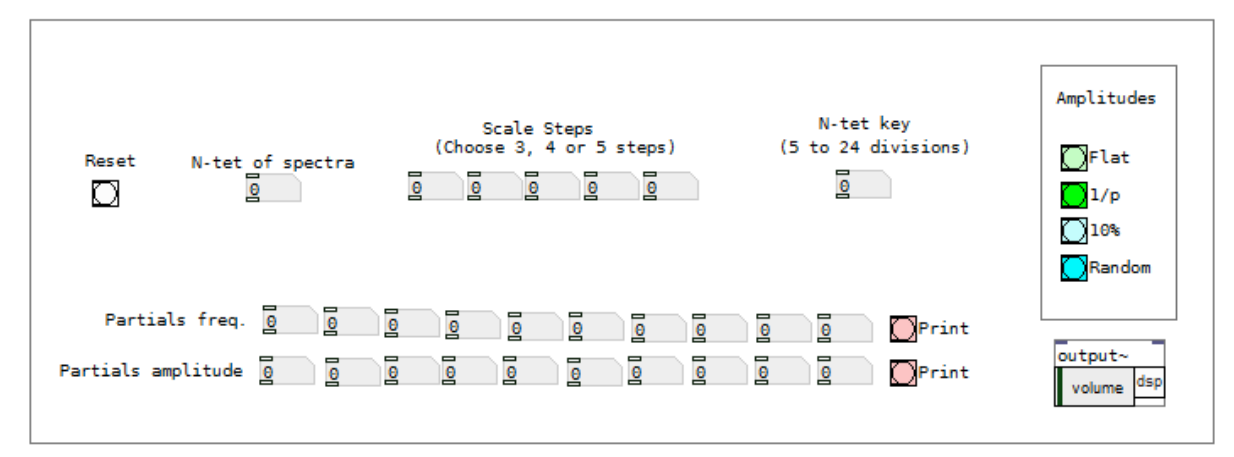

Fig. 3. The front-end of the spectrum generator patch 
A synthesizer derived from [9] and presented in topic 4.3 is embedded inside, and an AKAI APC Key 25 MIDI controller, with a two-octave keyboard, has been used to control the patch. The choice of MIDI numbers that control the patch is based on the number of keys available on the keyboard, and its potentiometer is programmed to manipulate the amplitudes of partials.

\subsection{The scale generator}

The algorithm that generates equal tempered scales uses the corresponding MIDI number of the keyboard to represent a n-tet scale step and sends bangs to start the process. When the bang is activated, the computer multiplies a start frequency of 130.8 $\mathrm{Hz}$ by the scale ratio of the chosen equal tempered scale raised to the power $p$, where $p$ is the scale step that the MIDI value represents. The computer then converts the note frequency to MIDI so to send the value to the synthesizer. The algorithm is shown in the pseudo-code below.

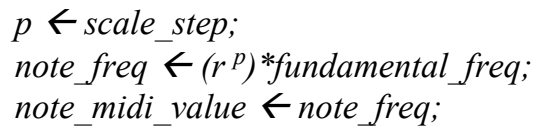

\subsection{The spectrum generator}

The spectrum generator consists in two modules: 1- a sequencer of partials derived from scale steps, and 2- a filter that separates the values sent by the counter according to the critical bandwidths.

To each iteration the sequencer outputs the initial number of the chosen step and the sum $($ step $+x n)$, where $x$ is the number of the iteration and $n$ is the number of divisions of the equal tempered scale (fig 4).

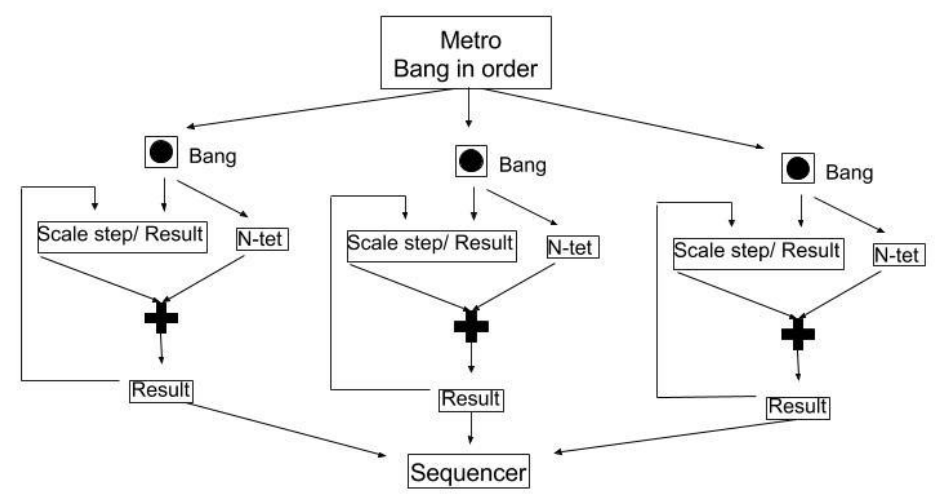

Fig. 4. The sequencer for scale steps in the spectrum generator 


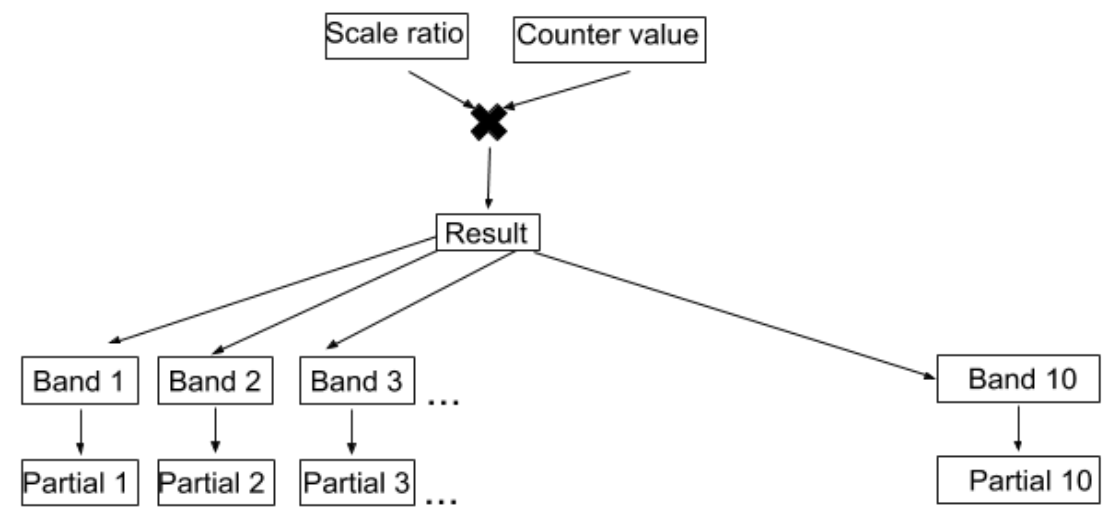

Fig. 5. The band filter of the spectrum generator

Then, the sequencer values are multiplied by the ratio of the chosen equal tempered scale. The corresponding values of the frequencies of the partials are then separated by critical bandwidths filters (fig. 5).

\section{The Evaluation of the timbres using dissonance curves}

An example spectrum with 8 partials was generated in the patch stated above, with the following specifications:

- Equal tempered scale that will generate the spectrum ( $N$-tet of spectra): 8-tet

- Steps of the scale that will be privileged in consonance: $2,4,6$ and 8.

- Amplitudes in an attenuation of $1 /$ partial

Resulting spectrum:

\begin{tabular}{|l|c|c|c|c|c|c|c|c|}
\hline $\begin{array}{l}\text { Partial } \\
\text { frequency }\end{array}$ & $\mathrm{F}$ & $2.37841 \mathrm{~F}$ & $4 \mathrm{~F}$ & $4.75683 \mathrm{~F}$ & $5.65686 \mathrm{~F}$ & $6.72717 \mathrm{~F}$ & $8 \mathrm{~F}$ & $9.51366 \mathrm{~F}$ \\
\hline $\begin{array}{l}\text { Partial } \\
\text { amplitude }\end{array}$ & 1 & 0.5 & 0.332 & 0.25 & 0.2 & 0.165 & 0.141 & 0.125 \\
\hline
\end{tabular}

This spectrum with a fundamental frequency of $\mathrm{F}=261.6 \mathrm{~Hz}$ is shown on fig. 6 . 


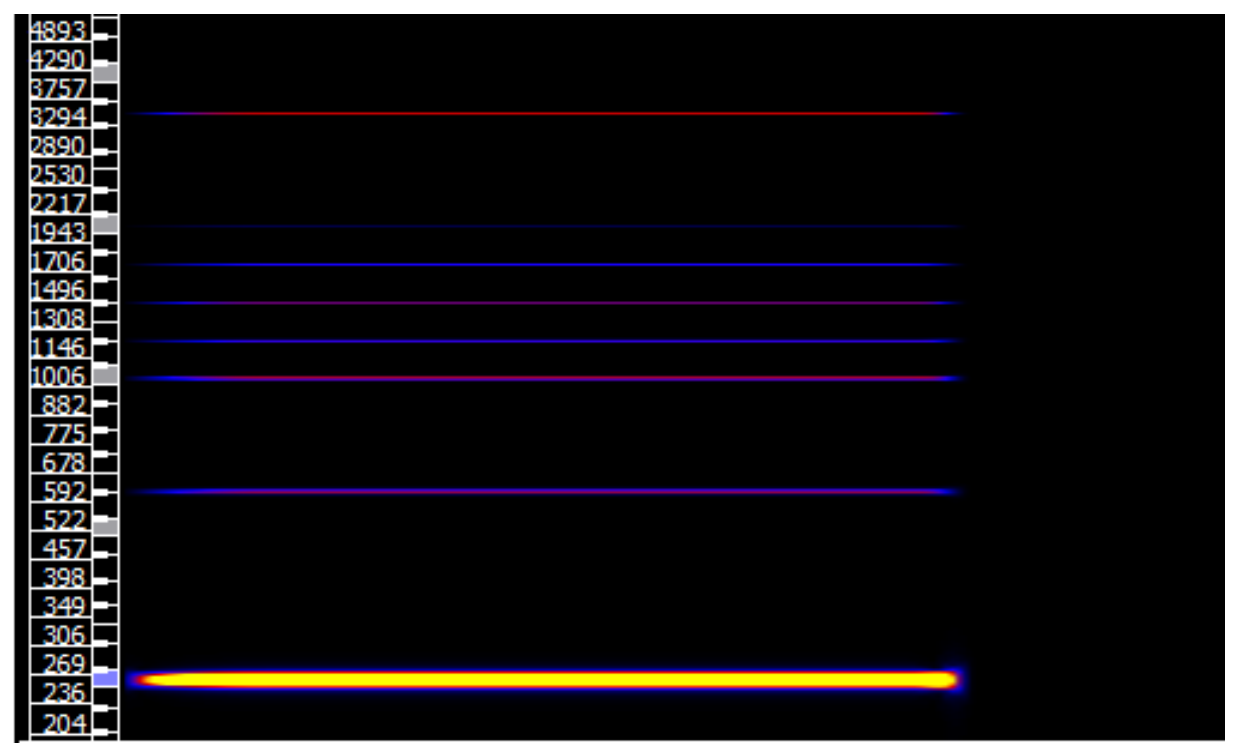

Fig. 6. Spectrogram of the timbre generated by the Pure Data patch, done with Sonic Visualiser. The horizontal axis represents time and the vertical, frequency channels. Notice the different partials' amplitudes encoded in color difference.

One can evaluate the efficiency of the method of relating scales and spectra by inspecting the minimum points of dissonance curves. The dissonance curve for this example was generated with GNU Octave using Sethares' MatLab code and adapting the parameters according to Vassilakis' model ${ }^{2}$.

The respective dissonance curve obtained for this spectrum is shown on fig. 7. The curve indicates that the highest levels of consonance are found at the steps 1 and 8 , followed by steps 2,6 and 4 . We can also verify that every step of the scale has a correspondent point of consonance. The curve generated by the chosen scale also exhibits a geometric symmetry in terms of local minimums, due to the fact that we have chosen equal distances between the privileged scale steps.

\footnotetext{
${ }^{2}$ See section 2 .
} 


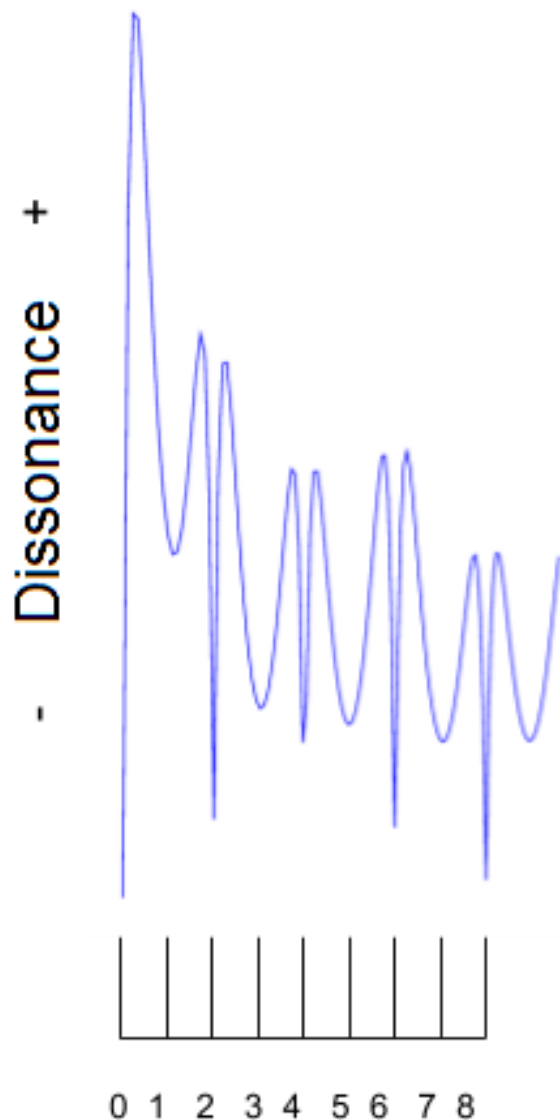

Fig. 7. The dissonance curve obtained for the designed 8-tet spectrum plotted with GNU Octave. The y axis represents the dissonance level and the $\mathrm{x}$ axis the frequencies, separated in scale steps.

\section{Conclusion and future steps}

The Pure Data patch was built aiming to create, through an automated process, a spectrum based on the technique of minimization of the dissonance for $n$-tet scales. Spectra that follow exhibit an intrinsic inharmonic structure. The procedure currently employs a set or rules to calculate partial frequencies and amplitudes, and our implementations have proved useful for testing the theory of sensory dissonance with any scale with 5-24 equal divisions and testing our hypothesis towards modeling it.

The analysis of the obtained spectrum using the dissonance models from Sethares and Vassilakis can confirm the efficacy of the presented method to generate a timbre with improved consonant properties. However, timbres generated using this 
technique are to be submitted to further subjective auditory tests, so we can test the presented model of consonance with spectra related to equal tempered scales.

Also, considering the non-stationary nature of musical performances, with varying dynamics and expression, it might be interesting to investigate the use of optimization algorithms to calculate adaptive frequency-amplitude ratios for satisfying instantaneous desired levels of dissonance during performance.

In terms of artistic applications, we need to improve the process of synthesis to achieve a time-variant spectra with a more dense texture than simple additive synthesis would permit. Besides that, it is necessary to find other interface (controller) solutions to execute such n-tet scales. A study based on an isomorphic keyboard and digital interfaces is currently under investigation for that.

\section{Acknowledgments}

The authors would like to thank NuSom (Research Centre on Sonology) and NEAC (Audio Engineering and Coding Center) of the University of São Paulo for hosting this research, and the financial support from the São Paulo State Research Foundation (FAPESP) to Micael Antunes da Silva, grant \#2016/09525-7.

\section{References}

1. Pierce, John R. "Attaining consonance in arbitrary scales." The Journal of the Acoustical Society of America vol. 40, n. 1, pp. 249-249 (1966)

2. Sethares, W. A.: Tuning, timbre, spectrum, scale. Springer-Verlag (2005)

3 Blackwood, Easley. "Modes and Chord Progressions in Equal Tunings." Perspectives of New Music vol. 29, n. 2, pp. 166-200 (1991)

4. Tenney, J.: A history of consonance and dissonance. Excelsior (1988)

5. Helmholtz, H. L. F.: On the sensation of tone as a psychological basis for the theory of harmony. Dover Publications (1954).

6. Plomp, R., Levelt, W. J. M.: Tonal consonance and critical bandwidth. Journal of the Acoustical Society of America, vol. 38, n. 4, pp. 548-568 (1965).

7. Terhardt, E.: Pitch, consonance, and harmony. The Journal of the Acoustical Society of America, vol. 55 n. 5, pp.1061-1069 (1974).

8. Vassilakis, P. N.: Perceptual and physical properties of amplitude fluctuation and their musical significance. Doctoral dissertation, University of California, Los Angeles (2001).

9. Silva, M. A.; Faria, R. R. A.: Lowering dissonance by relating spectra on equal tempered scales. In: Proceedings of the 12th International Symposium on Computer Music Multidisciplinary Research, 2016, São Paulo. Marseille: The Laboratory of Mechanics and Acoustics, 2016, pp.323-330 (2016). 


\section{ANEXO B - Artigo Apresentado - ClCTeM 2017}

A seguir, o artigo "An Algorithm to Generate Spectra by Decreasing Sensory Dissonance in Equal Tempered Scales" (um algoritmo para gerar espectros através da diminuição da dissonância sensorial em escalas com temperamento por igual) (SILVA; BAYEH; FARIA, 2017), apresentado na forma de apresentação oral no III Congreso Internacional de Ciencia y Tecnología Musical, em outubro de 2017 em Buenos Aires, Argentina. 


\section{AN ALGORITHM TO GENERATE SPECTRA BY DECREASING SENSORY DISSONANCE IN EQUAL TEMPERED SCALES}

\author{
Micael Antunes da Silva \\ University of São Paulo \\ School of Arts and \\ Communications
}

\author{
Rebeca Bayeh \\ University of São Paulo \\ Institute of Physics
}

\author{
Regis Rossi Alves Faria \\ University of São Paulo \\ Faculty of Philosophy, \\ Sciences and Letters of \\ Ribeirão Preto
}

\begin{abstract}
This paper presents some established models in sensory dissonance and an algorithm for synthesizing spectra by minimizing the sensory dissonance between notes in equal tempered scales. The ear physiology and the concept of critical bandwidths developed by Zwicker [15] are detailed and a method of spectral modelling based on Pierce's [7] and Sethares' [12] work is described. The algorithm to generate the spectra according to this method is presented in pseudocode and Sethares' algorithm for plotting dissonance curves is adapted in order to visualize the dissonance curves of some of the spectra obtained.
\end{abstract}

\section{INTRODUCTION}

The concept of sensory dissonance has its origin in Helmholtz's theory of beats [5] and was revised in the work of Plomp and Levelt [8] that found a correlation between sensory dissonance and the concept of critical bandwidth introduced by Zwicker based on subjective tests [15].

There have been many speculations concerning models of sensory dissonance in sound spectra. We first highlight Clarence Barlow's model [1], based on Hutchinson and Knoppoff [6] work and on loudness and masking models ${ }^{1}$. Sethares' model, on the other hand, was based on an approximation of Plomp and Levelt's curve. This model was reviewed by Vassilakis [14], who changed parameters to estimate dissonance with different amplitudes between the partial ones.

In his work, Vassilakis performed a subjective test that asked participants to estimate the level of dissonance and roughness of harmonic sounds, and compared these results with the models of Helmholtz [5], Hutchinson and Knoppoff [6] and his own work [14], demonstrating that the model proposed represents better the sensation of dissonance. We will use in our work the model of Vassilakis [14].
Based on these models, many works are interesting in modeling the sensation of dissonance in sound spectra using sound synthesis techniques, as found in the works of Pierce [7] and Sethares [12]. In this work, we present an algorithm that generates spectra with reduced level of sensory dissonance in equal tempered scales, generating inharmonic spectra. These processes of synthesis are still under investigation, but some results obtained in subjective tests can demonstrate the efficiency in the modelling of sensory dissonance with inharmonic spectra, as found in the work of Geary [3].

\section{PHYSIOLOGY OF HEARING}

The auditory sensation of a sound is partially conditioned to the physical nature of the stimulus and partially conditioned to the biological structure responsible for hearing.

In mammals, the ear mediates the hearing, and is sensitive to sound stimulus, gravity and head movements. The transduction from mechanical stimulus to electrochemical signals occurs in the organ of Corti, located in the cochlea [11].

The cochlea is a spiraled cavity that contains three ducts: the vestibular duct, the tympanic duct and the cochlear duct, which is separated from the fist by Reissner membrane and from the second by the basilar membrane. The organ of Corti is located above the basilar membrane and is constituted by hair cells powered by the electric potential difference between the endolymph, located inside the cochlear duct, and the perilymph, located inside the vestibular and the tympanic ducts.

The round window, found in the extremity of the cochlear duct, works as a piston that oscillates generating waves in the basilar membrane. Through wave interference, the maximum amplitude of the resulting wave excites a specific region of the basilar membrane, which is conditioned to the original pitches of the sound stimulus.

The stereocilia of the hair cells in the organ of Corti convert the vibrations into nerve impulses that reach the

\footnotetext{
${ }^{1}$ See Porres [9].
} 
central nervous system and are then processed and interpreted as a sound [2].

The vibrations of the basilar membrane start in its basis and propagate to its apex. Low pitches excite the hair cells located near to the apex region, and high pitches excite the hair cells located in the basis region, so that different neuron populations are stimulated according to the frequencies of the sound stimulus. The higher the pitch of the sound, the smaller the excited region of the basilar membrane will be [10]. Helmholtz compared, in his book "On the Sensations of Tone as a Physiological Basis for the Theory of Music", the selective pitch responses in the basilar membrane and the mathematical decomposition of the signal via Fourier transform [5].

This concept was responsible for the elaboration of innumerable psychoacoustics models for sensory dissonance, including Zwicker's model of bandwidths.

\section{CRITICAL BANDWIDTH}

Many models and subjective experiments were developed aiming to model critical bandwidths. Zwicker, who created the "Munich critical bands" and introduced the unity "Barks", created the most widespread model.

The critical bandwidths are frequencies bandwidths within which two tones played simultaneously cause auditory masking. Hence, they are based upon human ear's frequency analysis, being directly related to the basilar membrane and to roughness effects.

The critical bands are usually smaller than one-thirdoctave in extension and each one is associated to a number, usually represented by $z$ and given in Barks, being the critical-band number zero associated to frequency zero. Critical-band-numbers differences smaller than one Bark indicate that the two tones associated to them belong to the same critical band [4].

The Bark scale has no analytic expression, but Traunmüller [13] proposed a formula to convert frequency to critical-band number, as shown in equations 1 to 4 .

$$
z^{\prime}=\frac{26.81 f}{1960+f}-0.53
$$

If $z^{\prime}<2.0$ Bark, then:

$$
z=z^{\prime}+0.15\left(2.0-z^{\prime}\right)
$$

If $z^{\prime}>20.1$ Bark, then

$$
z=z^{\prime}+0.22\left(z^{\prime}-20.1\right)
$$

Otherwise:

$$
z=z^{\prime}
$$

\section{A METHOD TO GENERATE SPECTRA BASED ON DISSONANCE MODELS}

Based on the works of Pierce [7] and Sethares [12] on the construction of inharmonic spectra related with arbitrary scales, a method to generate spectra by minimizing dissonance has been developed in equal tempered scales. The method is divided into three steps: 1- Calculation of the scale ratio; 2- Choice of the partials that will be privileged; 3- Selection of the partials using a critical bandwidth filter. These steps are illustrated in Figure 1.

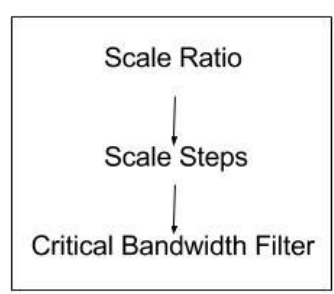

Figure 1. Steps of the developed method.

The calculation of the scale ratio aligns the partials of the spectrum with the scale steps. The choice of the partials that will be privileged aims to model a spectrum with a harmonic tendency in terms of consonance, for future creative works. This step was based on the harmonic spectrum and on the spectra of Pierce [7] and Sethares [12]. The third step aims to separate these partials using a critical bandwidth filter, avoiding beats and roughness between the spectra partials. Zwicker's table of critical bandwidth [15] and the Equations 1 to 4 were used.

\section{AN ALGORITHM TO GENERATE SPECTRA BASED ON DISSONANCE MODELS}

The developed method was summarized in an algorithm to automatize the generation of spectra, as described below.

\subsection{Scale Ratio}

An equal tempered scale consists of any scale that divides an interval $i$ (for instance an octave) into $n$ equal parts. To calculate the frequencies of a $n$-tet scale starting by an initial frequency $f$, we have:

$$
f, f r, f r^{2}, f r^{3} \ldots f r^{n}
$$

The general formula to calculate the ratio $r$ of any $n$-tet scale is given by Equation 5 .

$$
r=\sqrt[n]{i}
$$

Hence, in a 12-tet scale, considering and interval of octave $(i=2)$ we have:

$$
r=\sqrt[12]{2}
$$


whose solution is rounded to $r=1.05046$.

\subsection{Scale Steps}

In order to calculate the scale steps of any equal tempered scale, we multiply the initial frequency by the scale ratio raised to the correspondent scale step. In our method, we model the spectrum using frequencies of the scale steps and their respective octaves. The octaves of any step of equal tempered scales can be determined according to Equation 7:

$$
O_{s}=r^{s+n}
$$

where $s$ is the chosen scale step. For instance, to calculate the octave of $f r^{2}$ (step 2) in an 8-tet scale with initial frequency $f$, we have $f r^{2+8}=f r^{10}$. The resultant set of partials will be then selected by the critical bandwidth filter.

\subsection{The Critical Bandwidth Filter}

Given the set of frequencies correspondent to the chosen scale steps, a bandwidth filter will exclude some of them in order to avoid that two partials are within the same critical band, minimizing the sensory dissonance.

Based on Zwicker's model for critical bands, the method described in this work filters the set of frequencies by selecting the first one and then calculating the difference between the following frequency with the previous selected one. If the difference between them are smaller than one Bark, the second frequency is excluded. If not, it is included. After that, every frequency bandwidth will be compared with the last selected frequency, and excluded if the difference is below one Bark.

\subsection{The Algorithm to Generate Spectra}

The described algorithm can be synthetized in the pseudocode shown below.

Get N, I, f_0;

Get number_steps;

steps [ ] $<-0$;

for $(j=0 ; j<$ number_steps; $j++)\{$

\}

Get steps[];

\%ratio calculation

$r=I^{\wedge}(1 / N)$;

\%step frequencies determination

$f[0]=f \_0$;

for $(j=1 ; j<=$ number_steps; $j++)\{$

\}

$f[j]<-f_{-} 0 * r^{\wedge}($ steps $[j])$;

for $(j=$ number_steps $+1 ; f[j]<20000 ; j++)\{$ steps $[j]=$ steps $[(j-$ number_steps $+N]$;

\}

$f[j]<-f_{-} O * r^{\wedge}($ steps $[j])$;

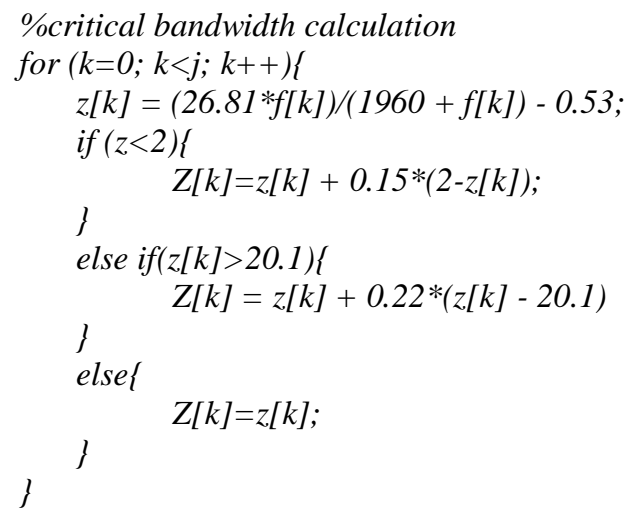

\%critical band filter

selected $[0]=f[0]$;

$l=0$;

for $(k=1 ; k<j ; k++)$ )

if $((Z[k]$-selected $[l])>=1)\{$

$l++$;

selected $[l]=f[k]$;

\}

$\gamma$

$\operatorname{print}($ selected []$)$

\section{DISCUSSION}

In order to validate the results obtained by using the described algorithm, two dissonance curves were drawn using Sethares' MatLab code [12] adapted according to Vassilakis model of sensory dissonance [14], both corresponding to the 8-tet scale and privileged steps 2, 4, 6 and 8 , with initial frequencies of $440 \mathrm{~Hz}$ and $1760 \mathrm{~Hz}$, as shown in Figures 2 and 3. 


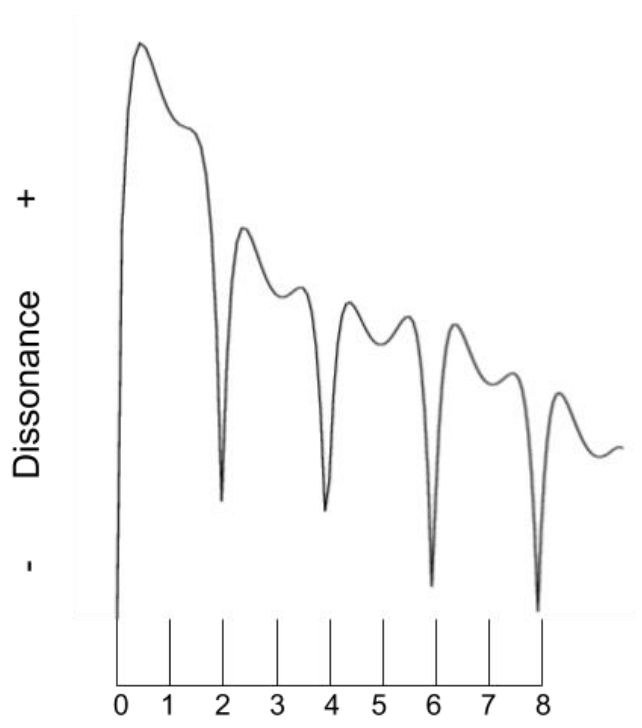

Figure 2. Dissonance curve; $\mathrm{f}_{0}=440 \mathrm{~Hz}$.

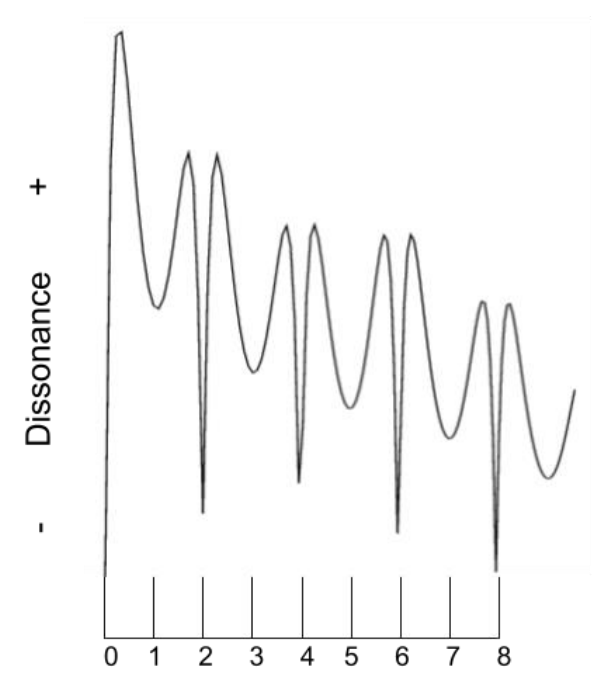

Figure 3. Dissonance curve; $\mathrm{f}_{0}=1760 \mathrm{~Hz}$.

The spectrum partials generated by our algorithm are: $f$, 1.19f, $1.68 f, 22.38 f, 2.83 f, 3.36 f$, $4 f$ for $f=440 \mathrm{~Hz}$ and $f$, 1.19f, 1.41f, 1.68f, $2 f, 2.38 f, 3.36 f$, $4 f$ for $f=1760 \mathrm{~Hz}$, with amplitudes of $1 / p$.

The selected partials were provisionally plotted with amplitudes $1 / p$, where $p$ is the number of the partial. It is still necessary to discuss the amplitude choices that will better dialogue with the resultant sensory dissonance.

From the dissonance curves we observe that, meanwhile the dissonance levels decrease as the register increases, the dissonances of the privileged steps constitute local minima that will be useful to synthetize timbres for artistic applications. However, it is still necessary to analyse methods of choice of privileged scale steps, given the limitations that the critical band filter imposes when the chosen partials belong to the same critical band.

We are currently developing a parameter associated with the "efficacy level" for future implementation. This parameter will be displayed to the user so that they will know the efficiency of their choice of privileged scale steps in terms of roughness minimization.

\section{CONCLUSIONS AND FUTURE STEPS}

The presented algorithm was demonstrated to be suitable for the construction of spectra that reduce the sensory dissonance in equal tempered scales. However, it is still necessary to include methods to determine the amplitudes of the partials that will be used, whose models are still under discussion.

The algorithm will serve as a base to improve a PureData patch that generates spectra in equal tempered scales, currently being developed. A further MatLab implementation is being developed for psychoacoustical investigations.

\section{ACKNOWLEDGMENTS}

The authors would like to thank NuSom (Research Centre on Sonology) and NEAC (Audio Engineering and Coding Center) of the University of São Paulo for hosting this research, and the financial support from the São Paulo State Research Foundation (FAPESP) to Micael Antunes da Silva, grant \#2016/09525-7.

\section{REFERENCES}

[1] Barlow, C. "Von der Musiquantenlehre", in Feedback Paper 34, Feedback Studio Verlag, Colônia, 2008.

[2] Bento, R.F. Tratado de Otologia. $2^{\mathrm{a}}$ edição. Editora Atheneu, 2013.

[3] Geary, J.M. "Consonance and dissonance of pairs of inharmonic sounds", in The Journal of the Acoustical Society of America, 67.5, 1980. pp. 1785-1789.

[4] Hartmann, W.M. Signals, Sound, and Sensation (Modern Acoustics and Signal Processing). Corrected edition. American Institute of Physics, 2004.

[5] Helmholtz, H.L.F.; Ellis, A.J.. On the Sensations of Tone as a Physiological Basis for the Theory of Music. Second English Edition. Dover Publications, 1954.

[6] HUTCHINSON, W.; KNOPOFF, L. "The acoustic component of Western consonance", in Journal of New Music Research, v. 7, n. 1, 1978, pp. 1-29.

[7] Pierce, J. R. Pierce. "Attaining consonance in arbitrary scales" in The Journal of the Acoustical Society of America 40.1, 1966, pp. 249-249.

[8] Plomp, R.; Levelt, W.J.M. "Tonal consonance and critical bandwidth", in The journal of the Acoustical Society of America 38.4, 1965, pp. 548-560. 
[9] Porres, A.T. Modelos psicoacústicos de dissonância para eletrônica ao vivo. Diss. Universidade de São Paulo, 2012, pp. 47-48.

[10] Roederer, J.G. Introdução à Física e à Psicofísica da Música. Edusp, 2002.

[11] Ruggero, M.A. "Responses to sound of the basilar membrane of the mammalian cochlea", in Current Opinion in Neurobiology. 2(4), 1992, pp. 449-456.

[12] Sethares, W.A. Tuning, Timbre, Spectrum, Scale. Springer Science \& Business Media, 2004.

[13] Traunmüller, H. "Analytical expressions for the tonotopic sensory scale", in The Journal of the Acoustical Society of America 88.1, 1990, pp. 97-100.

[14] Vassilakis, P.N. Perceptual and physical properties of amplitude fluctuation and their musical significance. Diss. University of California, Los Angeles, 2001.

[15] Zwicker, E.; Flottorp, G.; Stevens, S.S. "Critical bandwidth in loudness summation", in The Journal of the Acoustical Society of America 29.5, 1957, pp. 548557. 


\title{
ANEXO C - Código em C - Cálculo e Filtra- gem de Bandas Críticas
}

\author{
Abaixo, o código em $\mathrm{C}$ desenvolvido para cálculo e filtragem de de frequências de \\ acordo com os modelos de Munique e de Cambridge de bandas críticas.

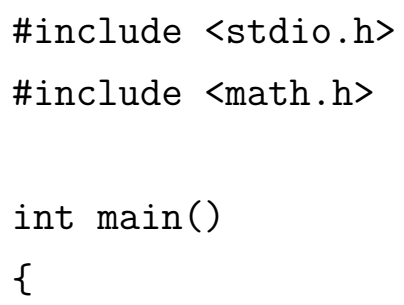


em ordem crescente: \n", N);

for $(i=0 ; i<N ; i++) \operatorname{scanf}(1 " \% f ", \& f[i])$;

//calculo das bandas criticas

for $(i=0 ; i<N ; i++)\{$

$z[i]=((26.81 * f[i]) /(1960.0+f[i]))-0.53$;

if $(z[i]<2.0) Z[i]=z[i]+(0.15 *(2.0-z[i]))$;

else if $(z[i]>20.1) Z[i]=z[i]+(0.22 *(z[i]-20.1))$;

else $Z[i]=z[i]$;

$\operatorname{cam}[i]=9.26 * \log (0.00437 * f[i]+1)$;

\}

//filtro de bandas criticas

selected $[0]=f[0]$;

for $(i=1 ; i<N ; i++)\{$

if $((Z[i]-Z[s])>=1)\{$

selected $[s+1]=f[i]$;

s++;

\}

\}

selectedCam $[0]=f[0]$;

for $(i=1 ; i<N ; i++)\{$

if $((\operatorname{cam}[i]-\operatorname{cam}[\mathrm{S}])>=1)\{$

selectedCam $[S+1]=f[i]$;

$\mathrm{S}++$;

\}

\}

printf("As bandas criticas sao: $\backslash n ")$;

for $(j=0 ; j<N ; j++) \operatorname{printf}(11 \% .2 f \mathrm{~Hz}: \% .2 f$ Barks ou $\% .2 f$ Cams $\backslash n "$, $f[j], Z[j], \operatorname{cam}[j])$; 
printf("As \%d frequencias do espectro filtrado pelo modelo de Munique sao: $(n ", s+1)$;

for $(j=0 ; j<s+1 ; j++)$ printf $(1 \% .2 f \mathrm{~Hz} "$, selected $[j])$;

printf("\n E as \%d frequencias do espectro filtrado pelo modelo de Cambridge sao: $\backslash \mathrm{n} ", \mathrm{~S}+1$ );

for $(j=0 ; j<S+1 ; j++)$ printf( $(1 \% .2 f \mathrm{~Hz} "$, selectedCam $[j])$;

printf("usando a escala de Cambridge. \n");

return 0 ;

\} 



\section{ANEXO D - Códigos em MatLab - Curvas de Dissonância}

Abaixo, encontra-se o código adaptado de Sethares (SETHARES, 2005a) de acordo com o modelo descrito por (VASSILAKIS, 2001).

function d=vassilakis ( $f$ vec, amp)

Dstar=0.24; $\mathrm{S} 1=0.0207 ; \mathrm{S} 2=18.96 ; \mathrm{C} 1=5 ; \mathrm{C} 2=-5$;

$\mathrm{A} 1=-3.51 ; \mathrm{A} 2=-5.75 ;$ firstpass $=1$;

$\mathrm{N}=$ length (fvec);

$[$ fvec, ind $]=\operatorname{sort}($ fvec $)$;

ams $=\operatorname{amp}($ ind $)$;

$\mathrm{D}=0$;

for $i=2: N$

Fmin=fvec $(1: \mathrm{N}-\mathrm{i}+1)$;

$\mathrm{S}=$ Dstar.$/(\mathrm{S} 1 *$ Fmin+S2)

Fdif $=f \operatorname{vec}(i: N)-f \operatorname{vec}(1: N-i+1)$;

$\mathrm{a}=(\operatorname{ams}(\mathrm{i}: \mathrm{N}) . * \operatorname{ams}(1: \mathrm{N}-\mathrm{i}+1)) . \wedge(0.1)$;

Dnew $=$ a.$*((\mathrm{C} 1 * \exp (\mathrm{A} 1 * \mathrm{~S} . * \mathrm{Fdif})+\mathrm{C} 2 * \exp (\mathrm{A} 2 * \mathrm{~S} . * \mathrm{Fdif})) * 0.5 *$

$((2 . * \operatorname{ams}(1: N-i+1)) /(\operatorname{ams}(i: N)+\operatorname{ams}(1: N-i+1))) \cdot-3 \cdot 11)$;

$\mathrm{D}=\mathrm{D}+$ Dnew*ones $(\text { size }(\text { Dnew }))^{\prime}$;

end

$\mathrm{d}=\mathrm{D}$;

Aqui, o código para implementação da função determinada acima, que dever ser salva no mesmo diretório. As frequências e amplitudes do espectro de entrada são introduzidas nos vetores freq e $a m p$, e estão omitidas.

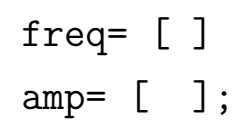

range $=2.3$;

inc $=0.01 ; \operatorname{diss}=[0]$;

for alpha $=1+$ inc: inc: range,

$f=$ [freq alpha*freq] ; 
$\mathrm{a}=[\mathrm{amp}, \mathrm{amp}]$;

$d=$ vassilakis $(f, a)$;

diss $=[$ diss d] ;

end

semilogx (1: inc:range, diss)

Por fim, segue abaixo o código utilizado para geração das três curvas de dissonância utilizando os dois filtros de espectro.

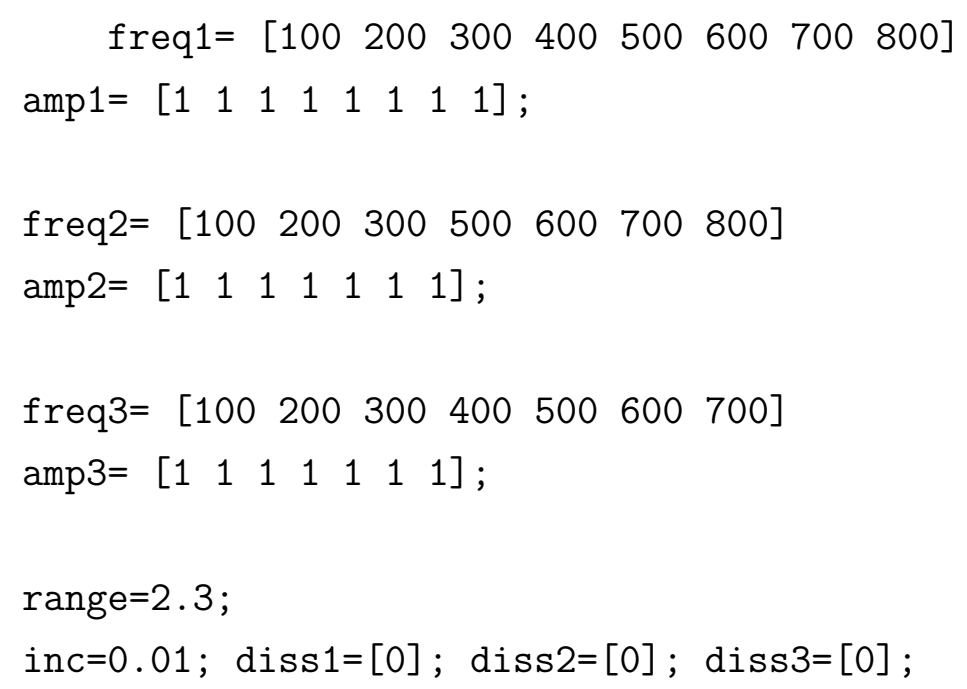


$\operatorname{diss} 3=[\operatorname{diss} 3 d]$;

end

semilogx (1: inc:range, diss 1$)$

hold on;

semilogx (1:inc:range, diss 2$)$

hold on;

semilogx (1:inc:range, diss 3$)$ 